\title{
Genetic Diversity and Association Study of Aromatics in Grapevine
}

\author{
Xiaoxu Yang, Yinshan Guo', Junchi Zhu, Zaozhu Niu, Guangli Shi, Zhendong Liu, Kun Li, \\ and Xiuwu Guo ${ }^{1}$ \\ Pomology Department, College of Horticulture, Shenyang Agricultural University, 120 Dongling \\ Road, 110866 Shenyang, Liaoning, China
}

\begin{abstract}
AdDitional INDEX words. SSR, Vitis, monoterpene, GWAS
Abstract. Monoterpenoid metabolism and aroma compounds are influenced by genetic characteristics. Linalool, $\alpha$-terpineol, nerol, and geraniol are primary monoterpenoids that have previously been studied in grape (Vitis vinifera) berries. Previous studies were restricted by the lack of relevant studies investigating population structure and the regulatory mechanism underlying monoterpenoid synthesis. In this study, a total of 1133 alleles were amplified, with each locus having on average 6.06 alleles. We also assessed the genetic variability among the genotypes based on 187 microsatellite primer pairs amplified in 96 grape genotypes. The results of the phylogenetic tree analysis showed that the grapevine accessions grouped into five genetic clusters that largely coincided with the recognized species classification and the result of principal coordinates analysis (PCoA). The molecular characterization of these accessions provides insight into genetic diversity, population structure, and linkage disequilibrium (LD) in grapevines. A total of 51 quantitative trait loci (QTLs) were detected that were significantly associated with linalool, $\alpha$-terpineol, nerol, and geraniol. We found that Deoxyxylulose phosphate synthase $(D X S)$ was located in the region UDV060 on linkage group (LG) 5, whereas Farnesyl diphosphate synthase (FPPS) and Hydroxymethylbutenyl diphosphate reductase (HDR) were located in the VLG19-I-1 and VLG3-A-1 regions, respectively. These novel QTLs will potentially assist in the screening of aroma compounds in grapevines.
\end{abstract}

Flavor and aroma compounds belong to the large group of secondary metabolites in grapevine berries (Lund and Bohlmann, 2006). Monoterpenoids are also responsible for aroma development in these berries, with the amount of monoterpenoids present substantially affecting aromatic characteristics of grapevines. Linalool, $\alpha$-terpineol, nerol, and geraniol are major organic aromatic volatile compounds found in different groups (Mateo and Jimenez, 2000). Recently, aroma compounds have been the subject of many peer-reviewed research articles (Chacón et al., 2012; Chang et al., 2014; Ghaste et al., 2015; Maoz et al., 2016). Grape genetics, genomics studies, and simple sequence repeat (SSR) analysis have provided an efficient means of assessing genetic diversity and population structure in Vitis species. Huang et al. (2011) used 145 SSR primer pairs to compare the loci of 'Cabernet Sauvignon' (Vitis vinifera) and 'Riesling' ( $V$. vinifera) grapevines, with the results showing that 70 loci were heterozygous in at least one cultivar, whereas 72 were homozygous in both cultivars. Marrano et al. (2015) reported the genetic diversity, relationships, and population structure of 80 grapevine cultivars and 21 Vitis sylvestris accessions that originated from central Asia. The expanded coverage of the grapevine genetic structure in different areas has facilitated worldwide use of grapevine germplasm for diversification of the cultivated gene pool. However, despite these previous studies on the genetic diversity and structure of grapevine, further research is still needed to understand

Received for publication $21 \mathrm{Feb}$. 2017. Accepted for publication 4 May 2017. Financial support was provided by the National Natural Science Funds of China (grant number 31372021 and 31572085); the China Agriculture Research System (grant number CRAS-30-yz-6); and the Research project in Liaoning Province Science and Technology Department (grant number 2014204004).

${ }^{1}$ Corresponding authors. E-mail: guoxw1959@163.com or guoyinshan77@126. com. grapevine population structures. The methylerythritol phosphate (MEP) and mevalonate (MVA) pathways are the main monoterpene biosynthesis pathways in plants (Bohlmann and Keeling, 2008). The biosynthesis of flavor compounds has been shown to occur via the MEP pathway in berries (Luan and Wust, 2002). Several monoterpene synthases have been functionally catalyzed during monoterpenol biosynthesis including linalool, $\alpha$-terpineol, nerol, and geraniol. The early pathway genes are $D X S, D X S 1$, Deoxyxylylose phosphate reductoisomerase, and HDR. FPPS and Geranyl diphosphate synthase are middle pathway genes, and Linalool/nerolidol synthase, $\alpha$-Terpinneol synthase, E-aBergomotene synthase, and Germacrene D synthase are late pathway genes (Martin et al., 2012). These genes are involved in catalyzing monoterpenol biosynthesis at different stages in the MEP and MVA pathways, with the expression of some of them correlating with flavor compound accumulation (Martin et al., 2012).

In recent years, genome-wide association studies (GWAS) have gained preeminence (Atwell et al., 2010). Some crops and fruit have also been studied using LD analysis to infer the evolutionary history of species (Barnaud et al., 2006, 2010; Jannoo et al., 1999). Cultivated grapevine has previously been examined with long-range LD (Barnaud et al., 2006), making a GWAS feasible. GWAS is widely employed in QTL analyses in crops. GWAS has previously been used to examine verticillium wilt (Verticillium dahliae) resistance in cotton (Gossypium hirsutum) based on 158 cotton germplasm accessions (Zhao et al., 2014). Jun et al. (2008) reported that Satt571, Satt551, and Satt431 were significantly associated with soybean (Glycine max) seed protein content by GWAS. The results of a peach GWAS investigating pomological traits indicated three significant marker-trait associations based on 40 SSR markers in 94 peach (Prunus persica) cultivars (Forcada et al., 2013). A GWAS is, therefore, an effective means of analyzing 
in depth the relationship between markers and traits. In grapevine, the colocalization of $D X S$ and the QTLs on LG 5 for aroma compound levels indicated that $D X S$ functions in regulating metabolic flux through the MEP pathway (Battilana et al., 2009). Subsequent research further confirmed that the function of $D X S$ was effected through polymorphisms in the gene that potentially regulated and controlled terpenoid metabolism in grapevine (Battilana et al., 2011).

The aim of this investigation was to genotype a population of 96 grapevine germplasm accessions using genome-wide molecular markers and to explore the genetic structure and functional QTLs' association with aroma production in these grapevine accessions.

\section{Materials and Methods}

\section{Plant material and phenotypic evaluation}

The plant material consisted of 96 grapevine cultivars collected from the Shenyang Agriculture University in Shenyang (lat. 41 $49^{\prime} 24^{\prime \prime} \mathrm{N}$, long. $126^{\circ} 33^{\prime} 41^{\prime \prime} \mathrm{E}$ ), Liaoning Province, China. This included five species under the genus Vitis namely $V$. vinifera, $V$. vinifera $\times V$. labrusca, $V$. vinifera $\times V$. amurensis, $V$. amurensis, and $V$. labrusca (Supplemental Table 1 ), with the accessions selected to maximize flavor diversity. Berries were sampled when they were fully ripe mainly in Sept. 2014 and 2015 (sampling timing according to the berry
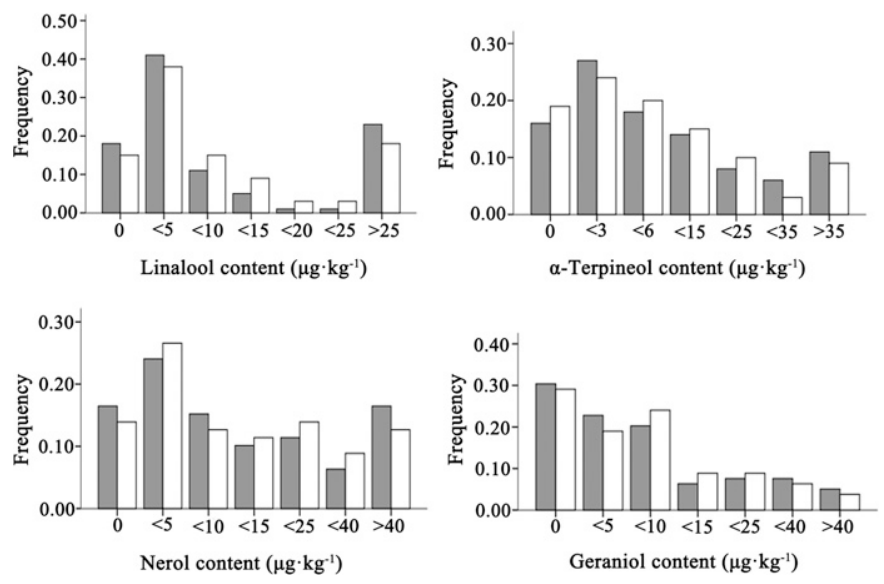

Fig. 1. The frequency distribution of linalool, $\alpha$-terpineol, nerol, and geraniol concentrations ratings in 2014 (gray bars) and 2015 (white bars). Phenotypic variations in aroma compounds were evaluated using GC-MS among the 96 grapevine accessions.

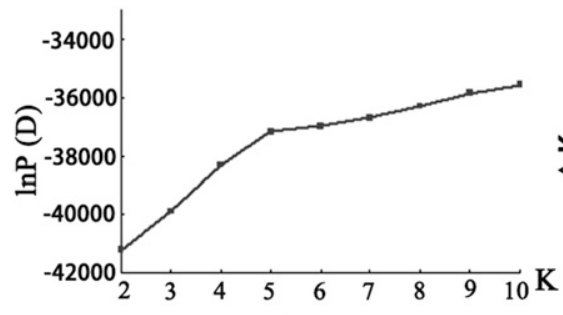

(A)

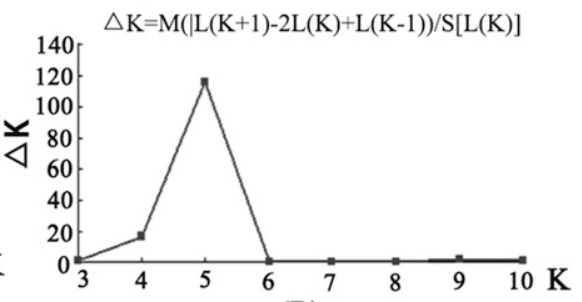

(B)
Fig. 2. Diagrams for $(\mathbf{A}) \ln P(D)$ and $(\mathbf{B}) \Delta \mathrm{K}$ of the grapevine lines subdivided into five groups based on 1133 alleles from 187 SSR primer pairs amplified in 96 individuals. $\mathrm{K}=$ number of genetic clusters, $\ln \mathrm{P}(\mathrm{D})$ and $\Delta \mathrm{K}=$ to determine the best $\mathrm{K}$. maturity features among cultivars), and $300 \mathrm{~g}$ of each sample was stored at $-80{ }^{\circ} \mathrm{C}$ for monoterpenoid analysis using gas chromatography-mass spectrometry (GC-MS). Levels of linalool, terpineol, nerol, and geraniol were evaluated using solidphase microextraction according to the method of $\mathrm{Wu}$ et al. (2009). The GC-MS oven program was as follows: step $1: 60^{\circ} \mathrm{C}$ for $3 \mathrm{~min}$; step $2: 12^{\circ} \mathrm{C} \cdot \mathrm{min}^{-1}$ to $100{ }^{\circ} \mathrm{C}$; step $3: 4{ }^{\circ} \mathrm{C} \cdot \mathrm{min}^{-1}$ to $210{ }^{\circ} \mathrm{C}$; and step 4: $210{ }^{\circ} \mathrm{C}$ for $3 \mathrm{~min}$. The GC-MS detector (7890A-5795C; Agilent, Santa Clara, CA) was scanned within a mass range of $\mathrm{m} \cdot \mathrm{z}^{-1} 30-500 \mathrm{amu}$. It was equipped with a VFmax column $(30 \mathrm{~m} \times 0.25 \mathrm{~mm} \times 0.25 \mu \mathrm{m}$, Agilent $)$, and helium (flow rate of $1.0 \mathrm{~mL} \cdot \mathrm{min}^{-1}$ ) was used as the carrier gas. Mass spectra were retrieved using the NIST11 spectral library. A calibration curve was obtained using a neutral grape 'Tenzan' ( $V$. vinifera); grapes of a similar size were added with linalool $\left(25 \mu \mathrm{g} \cdot \mathrm{kg}^{-1}\right)$, $\alpha$-terpineol $\left(25.1 \mu \mathrm{g} \cdot \mathrm{kg}^{-1}\right)$, nerol $\left(25.2 \mu \mathrm{g} \cdot \mathrm{kg}^{-1}\right)$, and geraniol $\left(25.1 \mu \mathrm{g} \cdot \mathrm{kg}^{-1}\right)$ (Tokyo Chemical Industry, Tokyo, Japan) dissolved in MilliQ (Millipore, Billerica, MA) water and ethanol $(1: 1, \mathrm{v} / \mathrm{v})$ to obtain a final concentration of $350 \mu \mathrm{g} \cdot \mathrm{kg}^{-1}$ (six scores) and to control the linearity of the curve up to $1 \mu \mathrm{g} \cdot \mathrm{kg}^{-1}$.

\section{DNA extraction and polymerase chain reaction}

Genomic DNA was extracted from $300 \mathrm{mg}$ of fresh young leaves from the shoot tips of individual vines in the experimental field using the modified cetyltrimethyl ammonium bromide method described by Hanania et al. (2004). DNA was quantified using electrophoresis on $0.8 \%$ agarose gels with lambda DNA as a standard (Guo et al., 2014).

Among the 713 pairs of SSR primers used in this experiment, 375 primer pairs were already published at the National Center for Biotechnology Information (NCBI, Bethesda, MD), and 338 pairs were designed by our group (Supplemental Table 2). All primers were uniformly distributed across the genome. Finally, we selected 187 pairs of SSR primers with clear polymorphic bands for use in this study. Polymerase chain reaction $(\mathrm{PCR})$ reactions were carried out in a total volume of $10 \mu \mathrm{L}$ comprising $10 \mathrm{ng}$ of genomic DNA, $5 \mu \mathrm{L}$ Premix Ex Taq Version 2.0 (Takara, Tokyo, Japan), and forward primer: $5 \mu \mathrm{M}$, reverse primer: $5 \mu \mathrm{M}$ then add double distilled water $\left(\mathrm{ddH}_{2} \mathrm{O}\right)$ to $10 \mu \mathrm{L}$. The PCR amplification was carried out according to the Premix Ex Taq Version 2.0 manufacturer's instructions. The amplification products were separated by electrophoresis on silver-stained $5 \%$ polyacrylamide gels run in $0.5 \times$ TBE buffer.

\section{Statistical analysis}

GeNeTIC DIVERSITY. The genetic diversity, number of alleles, heterozygosity, frequency of major alleles, and polymorphic information content of SSR markers were estimated using PowerMarker version 3.25 (Guo et al., 2007). The genetic variation was calculated using GenAlEx version 6.5 (Peakall and Smouse, 2012).

Genetic STRUCTURE. STRUCTURE version 2.3.4 (Pritchard et al., 2000a) was used to sort individuals into $\Delta \mathrm{K}$ clusters based on their genetic similarity. We ran STRUCTURE under the "admixture model" with a burn-in period of $1 \times 10^{4}$ followed by $1 \times$ $10^{5}$ replications of Markov chain Monte Carlo. The number of presumed clusters (K) was set from 2 to 10 , and the analysis was repeated five times. Phylogenetic analysis 
was estimated using the Neighbor-joining algorithm as implemented in PowerMarker version 3.25 and FigTree version 1.4.2 software (Liu and Muse, 2005). Nei's unbiased measures of genetic identity and genetic distance were performed with Popgene version 1.3.2 (Nei, 1978). Principal coordinates analysis was carried out using the GenAlEx 6.5 software (Peakall and Smouse, 2012).

LINKAGE DISEQUILIBRIUM AND ASSOCIATION ANALYSIS. Kinship coefficients and ancestry coefficients (Q-matrix) were used as covariates for the association studies general linear model constructed using STRUCTURE version 2.3.4 (Evanno et al., 2005; Pritchard et al., 2000b). LD analysis was estimated using Tassel 5.0 software (Bradbury et al., 2007). The LD plot was constructed using SPSS software (version 18.0.4; IBM Corp., Armonk, NY). The general linear model was combined with the Q-matrix to obtain association results using Tassel 5.0 software.

\section{Result and Discussion}

Phenotype And genetic diversity. Aromatic substance content was affected by climatic and cultivation management conditions. To understand the effect of the climate to differences in aroma accumulation in different year, we collected the main weather parameters for 2014 and 2015 in Shenyang county, Liaoning Province. The cumulative rainfall was $630 \mathrm{~mm}$ in 2015 and $513 \mathrm{~mm}$ in 2014. There was no significant difference for the average temperature and sunshine hours between the 2 years (Supplemental Fig. 1). The minor weather change had a small effect on the berry aroma in 2014 and 2015. For all associated aroma compounds, the aroma concentrations were slightly higher in 2015 than in 2014.

Phenotypic variations in aroma compounds were evaluated among the accessions. Linalool, $\alpha$-terpineol, nerol, and geraniol contents segregated, and the distribution for $\alpha$-terpineol was unimodal and continuous for both years. Whereas the concentration of linalool was high $\left(>25 \mu \mathrm{g} \cdot \mathrm{kg}^{-1}\right)$ in about $20 \%$ of the total accessions, among the samples containing geraniol, more than $70 \%$ were in the range of $0-10 \mu \mathrm{g} \cdot \mathrm{kg}^{-1}$. More than $40 \%$ of the total accessions had a nerol concentration lower than $5 \mu \mathrm{g} \cdot \mathrm{kg}^{-1}$ (Fig. 1). A total of 1133 alleles and 2315 genotypes were detected using 187 SSRs in 96 individuals, with an average of 6.06 alleles and 12.38 genotypes per locus. These results were higher than those obtained in previous studies of grapevine genetic diversity (Moreno-Sanz et al., 2011), potentially because of the high heterogeneity of the accessions. The genetic diversity, frequency of major alleles, and polymorphic information content were 0.60 (0.03-0.87), 0.53 (0.22-0.98), and $0.56(0.03-0.85)$, respectively (Supplemental Table 3$)$. The observed heterozygosity values varied from 0.01 (UDV044, LG 13 ) to 0.94 (VLG19-C-1, LG 19), with an average of 0.44 , and the value availability of markers varied from 0.56 to 1.00 with an average of 0.94 . This result may have arisen because of the high degree of human selection the accessions were subjected to (Sefc et al., 2000).
Table 1. Phylogenetic analysis grouped the 96 grapevines into five genetic clusters that were largely consistent with species classification and mating system. Nei's unbiased measures of genetic identity (above diagonal) and genetic distance (below diagonal) of the 96 accessions were performed with Popgene [version 1.3.2 (Nei, 1978)] and analyzing the genetic identity and genetic distance between each pair of clusters.

\begin{tabular}{lcccccc}
\hline & & \multicolumn{5}{c}{ Genetic identity $^{\mathrm{z}}$} \\
\cline { 3 - 7 } & Clusters $^{\mathrm{y}}$ & $\mathrm{P} 1$ & $\mathrm{P} 2$ & $\mathrm{P} 3$ & $\mathrm{P} 4$ & $\mathrm{P} 5$ \\
\hline Genetic distance $^{\mathrm{x}}$ & $\mathrm{P} 1$ & - & 0.9305 & 0.8501 & 0.7158 & 0.5455 \\
& $\mathrm{P} 2$ & 0.072 & - & 0.8648 & 0.6686 & 0.5334 \\
& $\mathrm{P} 3$ & 0.1624 & 0.1452 & - & 0.7286 & 0.5192 \\
& $\mathrm{P} 4$ & 0.3344 & 0.4026 & 0.3167 & - & 0.6835 \\
& P5 & 0.6061 & 0.6285 & 0.6554 & 0.3806 & - \\
\hline
\end{tabular}

${ }^{\bar{z}}$ Genetic identity between clusters may contribute to further explain for genetic distance between different clusters.

${ }^{\mathrm{y}}$ Grapevines were clustered into five main genetic clusters designated P1 to P5.

${ }^{\mathrm{x}}$ The genetic distance between different clusters.

Genetic STRUCture. The value of clusters (K) was set from 2 to 10 . The $\mathrm{LnP}(\mathrm{D})$ value increased continuously with $\mathrm{K}$ from 2 to 15 (Fig. 2A), and the highest $\Delta \mathrm{K}$ (Evanno et al., 2005) value $(\mathrm{K}=5)$ was identified (Fig. 2B). Accordingly, 96 accessions were clustered into five main genetic clusters designated P1 to P5 (Fig. 3). Phylogenetic analysis grouped the 96 grapevines into five genetic clusters that were largely consistent with species classification and mating system. PCoA also showed the differentiation between genetic clusters, although there were some overlapping zones (Supplemental Fig. 2). The $x$ - and $y$-axes accounted for $7.07 \%$ and $5.34 \%$ of the molecular variation, respectively. Some of the 
accessions from P1, P2, and P3 could Table 2. A total of 51 quantitative trait loci (QTLs) detected were significantly associated with not be completely separated indicating that these genetic clusters have a similar genetic background (Aradhya et al., 2003). The results were consistent with both the phylogenetic analysis and population structure analysis. Many $V$. vinifera species were found in P1 and P2, whereas P3 mainly consisted of the 'Concord' and some $V$. vinifera $\times V$. labrusca hybrids. P4 mainly consisted of $V$. vinifera $\times V$. amurensis, whereas P5 encompassed the Vitis amurensis pedigree including $V$. vinifera $\times V$. amurensis cultivars such as Beijinghong and Zuoyouhong that were bred by the Chinese Academy of Agricultural Sciences (Fig. 3). Human selection and complex pedigrees are the major factors influencing the genetic structure of accessions (Aradhya et al., 2003; Myles et al., 2011). The genetic distance among different clusters in this study ranged from 0.0720 (between P1 and P2) to 0.6554 (between P3 and P5), and the genetic identity ranged from 0.5192 (between $\mathrm{P} 3$ and P5) to 0.9305 (between P1 and P2). There were greater genetic distance and lower genetic identity between P5 and the other genetic clusters (Table 1). These results indicate that $V$. amurensis was most distantly related to the other species, consistent with the study by Wen et al. (2011).

LINKAGE DISEQUILIBRIUM AND ASSOCIATION STUDY. LD decay was estimated by analyzing the kinship coefficients $\left(r^{2}\right)$ between each pair of markers. The relationships between $r^{2}$ and genetic distance (centimargans) for the 96 grapevine accessions are shown in Supplemental Fig. 3. As expected, the $r^{2}$ declined as the genetic distance increased. However, the plot also indicated a rapid decay of LD in grapevine, with the $r^{2}$ values declining to around 0.1 within 40-50 cM. Conversely, Barnaud et al. (2006) found that the $r^{2}$ values declined to around 0.1 within $5-10 \mathrm{cM}$ in some cultivate grapevines. This rate of decay is even more rapid than that observed in this study and is primarily due to the use of different accessions.

A total of 51 QTLs detected were significantly associated with aroma (Table 2). This study identified 6 QTLs related to linalool that were linalool, $\alpha$-terpineol, nerol, and geraniol in 96 grapevines in 2014 and 2015. The general linear model was combined with the ancestry coefficients (Q-matrix) to obtain association results using Tassel [version 5.0 (Bradbury et al., 2007)]. The value of p-Marker and Rsq-Marker may assist in identifying the relationship between QTLs and aroma.

\begin{tabular}{|c|c|c|c|c|c|}
\hline Aromatic substance and QTLs & $\mathrm{Yr}$ & Linkage group & Position $(\mathrm{M})^{\mathrm{z}}$ & p-Marker $^{y}$ & Rsq-Marker $^{x}$ \\
\hline \multicolumn{6}{|l|}{ Linalool } \\
\hline UDV060 & 2014 & 5 & 4.4 & $5.89 \mathrm{E}-05^{* *}$ & 0.5364 \\
\hline UDV060 & 2015 & 5 & 4.4 & $9.08 \mathrm{E}-06^{* *}$ & 0.5722 \\
\hline UDV011 & 2014 & 7 & 3.1 & $0.0035^{* *}$ & 0.3207 \\
\hline UDV011 & 2015 & 7 & 3.1 & $0.0063 * *$ & 0.3082 \\
\hline VLG107 & 2014 & 1 & 5.8 & $0.0137^{*}$ & 0.3099 \\
\hline VLG107 & 2015 & 1 & 5.8 & $0.0094 * *$ & 0.3238 \\
\hline VLG19-I-1 & 2014 & 19 & 8.5 & $0.0013 * *$ & 0.5849 \\
\hline VLG19-I-1 & 2015 & 19 & 8.5 & $0.0414^{*}$ & 0.6782 \\
\hline VLG5-F-1 & 2014 & 5 & 4.8 & $0.0331^{*}$ & 0.1195 \\
\hline VVIP17A & 2015 & 19 & 0.2 & $0.0107^{*}$ & 0.4458 \\
\hline \multicolumn{6}{|l|}{$\alpha$-Terpineol } \\
\hline VLG107 & 2014 & 1 & 5.8 & $5.37 \mathrm{E}-05^{* *}$ & 0.4099 \\
\hline VLG107 & 2015 & 1 & 5.8 & $0.0024 * *$ & 0.3646 \\
\hline VLG17-D-1 & 2014 & 17 & 3.5 & $0.0029 * *$ & 0.3829 \\
\hline VLG17-D-1 & 2015 & 17 & 3.5 & $0.0267^{*}$ & 0.3504 \\
\hline VLG5-H-1 & 2014 & 5 & 7.5 & $0.0118^{*}$ & 0.3262 \\
\hline VLG5-F-1 & 2014 & 5 & 5.5 & $0.0167^{*}$ & 0.1299 \\
\hline VVS29 & 2014 & 1 & 1 & $0.0319^{*}$ & 0.1427 \\
\hline UDV011 & 2014 & 7 & 3.1 & $0.0322^{*}$ & 0.2522 \\
\hline UDV005 & 2014 & 18 & 14.5 & $0.0495^{*}$ & 0.182 \\
\hline VMC3G9 & 2015 & 1 & 7.6 & $0.0016 * *$ & 0.2622 \\
\hline VMC2B3 & 2015 & 1 & 18.2 & $0.0189^{*}$ & 0.2529 \\
\hline VLG16-I-1 & 2015 & 16 & 8.5 & $0.0417^{*}$ & 0.2618 \\
\hline \multicolumn{6}{|l|}{ Nerol } \\
\hline VVIC72 & 2014 & 1 & 1.8 & $1.97 \mathrm{E}-09 * *$ & 0.4872 \\
\hline VVIC72 & 2015 & 1 & 1.8 & $2.16 \mathrm{E}-08^{* *}$ & 0.5741 \\
\hline VMC16D4 & 2014 & 5 & 16.5 & $0.0003 * *$ & 0.5498 \\
\hline VMC16D4 & 2015 & 5 & 16.5 & $8.36 \mathrm{E}-06^{* *}$ & 0.5719 \\
\hline VVIP17A & 2014 & 19 & 0.2 & $0.0004 * *$ & 0.5794 \\
\hline VVIP17A & 2015 & 19 & 0.2 & $1.76 \mathrm{E}-06^{* *}$ & 0.6694 \\
\hline VLG5-U-1 & 2014 & 5 & 20.5 & $0.0004 * *$ & 0.4857 \\
\hline VLG5-U-1 & 2015 & 5 & 20.5 & $5.1 \mathrm{E}-06^{* *}$ & 0.6152 \\
\hline VLG3-K-1 & 2014 & 3 & 10.5 & $0.0008 * *$ & 0.5129 \\
\hline VLG3-K-1 & 2015 & 3 & 10.5 & $5.01 \mathrm{E}-06^{* *}$ & 0.6711 \\
\hline VVIN52 & 2014 & 16 & 0.8 & $0.0016^{* *}$ & 0.6129 \\
\hline VVIN52 & 2015 & 16 & 0.8 & $0.0002 * *$ & 0.585 \\
\hline VLG2-E-1 & 2014 & 2 & 4.5 & $0.0018 * *$ & 0.2506 \\
\hline VLG2-E-1 & 2015 & 2 & 4.5 & $0.0005 * *$ & 0.3883 \\
\hline VLG5-F-1 & 2014 & 5 & 5.5 & $0.0048 * *$ & 0.1814 \\
\hline VLG5-F-1 & 2015 & 5 & 5.5 & $0.0034 * *$ & 0.3208 \\
\hline VMC6C10 & 2014 & 14 & 22 & $0.0331^{*}$ & 0.5361 \\
\hline VMC6C10 & 2015 & 14 & 22 & $0.0054 * *$ & 0.1909 \\
\hline VMC8C2 & 2014 & 2 & 17.5 & $0.0037 * *$ & 0.2791 \\
\hline VMCNG2E1 & 2014 & 4 & 5.3 & $0.0056^{* *}$ & 0.3245 \\
\hline VMCNG4B9 & 2014 & 6 & 18.5 & $0.0102^{*}$ & 0.2688 \\
\hline VMC8E6 & 2014 & 13 & 22.5 & $0.0221^{*}$ & 0.2688 \\
\hline UDV123 & 2014 & 14 & 8.5 & $0.0433^{*}$ & 0.0872 \\
\hline VLG6-E-1 & 2014 & 6 & 4.5 & $0.0498^{*}$ & 0.2607 \\
\hline VMCNG2H2-2 & 2015 & 8 & 7.2 & $0.0005 * *$ & 0.6602 \\
\hline VLG2-S-1 & 2015 & 2 & 18.5 & $0.0014 * *$ & 0.2808 \\
\hline VLG6-D-1 & 2015 & 6 & 3.5 & $0.0015^{* *}$ & 0.3056 \\
\hline VLG6-P-1 & 2015 & 6 & 15.5 & $0.0116^{*}$ & 0.5675 \\
\hline VMC6B11 & 2015 & 2 & 8.1 & $0.0218^{*}$ & 0.2902 \\
\hline
\end{tabular}


intensively distributed on chromo- Table 2. Continued.

somes LG1, LG5, LG7, and LG19. On LG1, LG 5, LG7, LG13, LG16, LG17, and LG18, we identified 9 QTLs associated with $\alpha$-terpineol. We also found 22 and 14 QTLs associated with nerol and geraniol, respectively. In this study, many QTLs were identified in both years, whereas others were detected only in the first year. Martin et al. (2012) has previously summarized the correlations between the transcript levels of genes associated with the MEP and MVA pathways and reported the relationships between monoterpene accumulation and the transcript levels of early terpenoid pathway genes. We can conclude here that the three markers UDV060, VLG19-I-1, and VLG3-A-1 were found in close proximity to the genes that correlated with aroma on LG5, LG19, and LG3, respectively (Fig. 4). All position information for QTLs and genes discussed in this study was obtained from NCBI and the Grape Genome Browser. Doligez et al. (2006) de-

\begin{tabular}{lccccc}
\hline Aromatic substance and QTLs & Yr & Linkage group & ${\text { Position }(M)^{\mathrm{z}}}^{2}$ & p-Marker $^{\mathrm{y}}$ & Rsq-Marker $^{\mathrm{x}}$ \\
\hline VLG102 & 2015 & 1 & 2.8 & $0.0297^{*}$ & 0.1016 \\
VLG19-D-1 & 2015 & 19 & 3.5 & $0.0445^{*}$ & 0.229 \\
Geraniol & & & & & \\
UDV041 & 2014 & 5 & 6.5 & $0.0290^{*}$ & 0.3062 \\
UDV041 & 2015 & 5 & 6.5 & $0.0003^{* *}$ & 0.4264 \\
VLG4-L-1 & 2014 & 4 & 11.5 & $0.0452^{*}$ & 0.1819 \\
VLG4-L-1 & 2015 & 4 & 11.5 & $0.0387^{*}$ & 0.1921 \\
VMC6D12 & 2014 & 9 & 4 & $0.0474^{*}$ & 0.2748 \\
VMC6D12 & 2015 & 9 & 4 & $0.0006^{* *}$ & 0.3959 \\
VLG3-A-1 & 2014 & 3 & 5 & $0.0056^{* *}$ & 0.3321 \\
VLG3-A-1 & 2015 & 3 & 5 & $0.0026^{* *}$ & 0.5026 \\
VLG5-F-1 & 2014 & 5 & 5.5 & $0.0010^{* *}$ & 0.1922 \\
VLG5-C-1 & 2014 & 5 & 2.5 & $0.0023^{* *}$ & 0.4235 \\
VMCNG2E1 & 2014 & 4 & 5.3 & $0.0102^{*}$ & 0.2606 \\
VLG5-G-1 & 2014 & 5 & 6.5 & $0.0278^{*}$ & 0.2414 \\
UDV011 & 2014 & 7 & 3.1 & $0.0474^{*}$ & 0.2482 \\
UDV127 & 2015 & 9 & 17.8 & $0.0007^{* *}$ & 0.2894 \\
VLG5-F-1 & 2015 & 5 & 5.5 & $0.0065^{* *}$ & 0.1576 \\
VVIV04 & 2015 & 7 & 17.5 & $0.0069^{* *}$ & 0.3038 \\
VMC6B11 & 2015 & 2 & 8.1 & $0.0182^{*}$ & 0.3037 \\
VLG107 & 2015 & 1 & 5.8 & $0.0390^{*}$ & 0.2776 \\
\hline
\end{tabular}

*, **Significant at $P<0.05$ or 0.01 , respectively.

${ }^{\mathrm{z}}$ Chromosome location of QTLs.

${ }^{\mathrm{y}}$ Significance level of markers.

${ }^{\mathrm{x}}$ Total explained phenotypic variation.

tected a major QTL for linalool,

nerol, and geraniol contents on LG 5

in the interval between VrZAG79 and VVC6. Monoterpene content was previously found to be significantly associated with $D X S$ (LOC100249323) in $V$. riparia and with VrZAG47 in 'Moscato Bianco' (Battilana et al., 2009). We found that DXS was nearest to UDV060 on LG 5 and that the QTLs were also located in the interval between VrZAG79 and VVC6 (Fig. 4A). $D X S$ was $0.6 \mathrm{M}$ distant from UDV060, 3.5 M from VVC6, 2.1 M from VrZAG79, and 0.7 M from VrZAG47. Emanuelli et al. (2010) found an association between $D X S$ and monoterpenoid levels in grapevine, whereas Sun et al. (2014) reported that terpene accumulation was related to $D X S$ transcript profiles in developing 'Alexandria' grapes $(V$. vinifera). In this study, UDV060 was shown to be related to monoterpenoid content and significantly associated with linalool (explained by $53.64 \%$ and $57.22 \%$ of the total variation in 2014 and 2015, respectively). Our results regarding the correlation between $D X S$ and monoterpenoid content are, therefore, consistent with those previously reported. We also found the specific monoterpenoids that were potentially associated with $D X S$ in grapevine. Other studies did not detect a significant increase in $D X S$ transcript abundance associated with increasing monoterpenoid levels during berry development in grapevine and, therefore, suggested that increases in monoterpenoids were caused by additional isopentenyl diphosphate precursors from the MVA pathway (Martin et al., 2012). FPPS (LOC100232975) was located close to VLG19-I-1 (0.4 M distant from FPPS) (Fig. 4B), but its transcript level remained unchanged during berry development (Martin et al., 2012). VLG19-I-1 related to monoterpenoid content and significantly associated with linalool (explained by $58.49 \%$ and $67.82 \%$ of the total variation in 2014 and 2015, respectively). To date, FPPS has not been reported to function in monoterpenoid

metabolism. However, it has been shown that the MEP pathway is the dominant route for the biosynthesis of monoterpene substrates in the grape berry (Luan and Wust, 2002). As FPPS is involved in the subordinate MVA pathway, it could be assumed that monoterpene biosynthesis would be less affected by changes in the expression of FPPS. However, as FPPS is the only middle terpenoid pathway enzyme in the MVA pathway, its function in monoterpene biosynthesis should not be ignored. We also need to consider the possibility of complex gene interactions in both pathways. The HDR (LOC100267479) synthase was identified close to VLG3-A-1 (0.3 M distant from $H D R)$ and was significantly associated with geraniol (explained by $33.21 \%$ and $50.26 \%$ of the total variation in 2014 and 2015 , respectively) (Fig. 4C). In addition, HDR transcript levels increased significantly during berry development suggesting that it may also be associated with monoterpene biosynthesis in grapevine (Wen et al., 2015). Sun et al. (2014) also confirmed a positive correlation between the transcript profile of $H D R$ and monoterpene accumulation. Research has shown that the expression profiles of HDR and FPPS could serve as biomarkers for monoterpenol-glycoside accumulation during berry development (Martin et al., 2010). Taken together, these results suggest that $H D R$ may play an important role in monoterpenoid metabolism. Whereas few articles have, to date, been devoted to understanding the roles of FPPS and HDR, their functions in monoterpene biosynthesis should be further investigated.

In summary, this study identified five genetic clusters that were consistent with species classification and mating system. We also used a GWAS to identify three QTLs that lie close to the functional genes associated with aroma compounds. These novel QTLs may contribute to further association studies and 


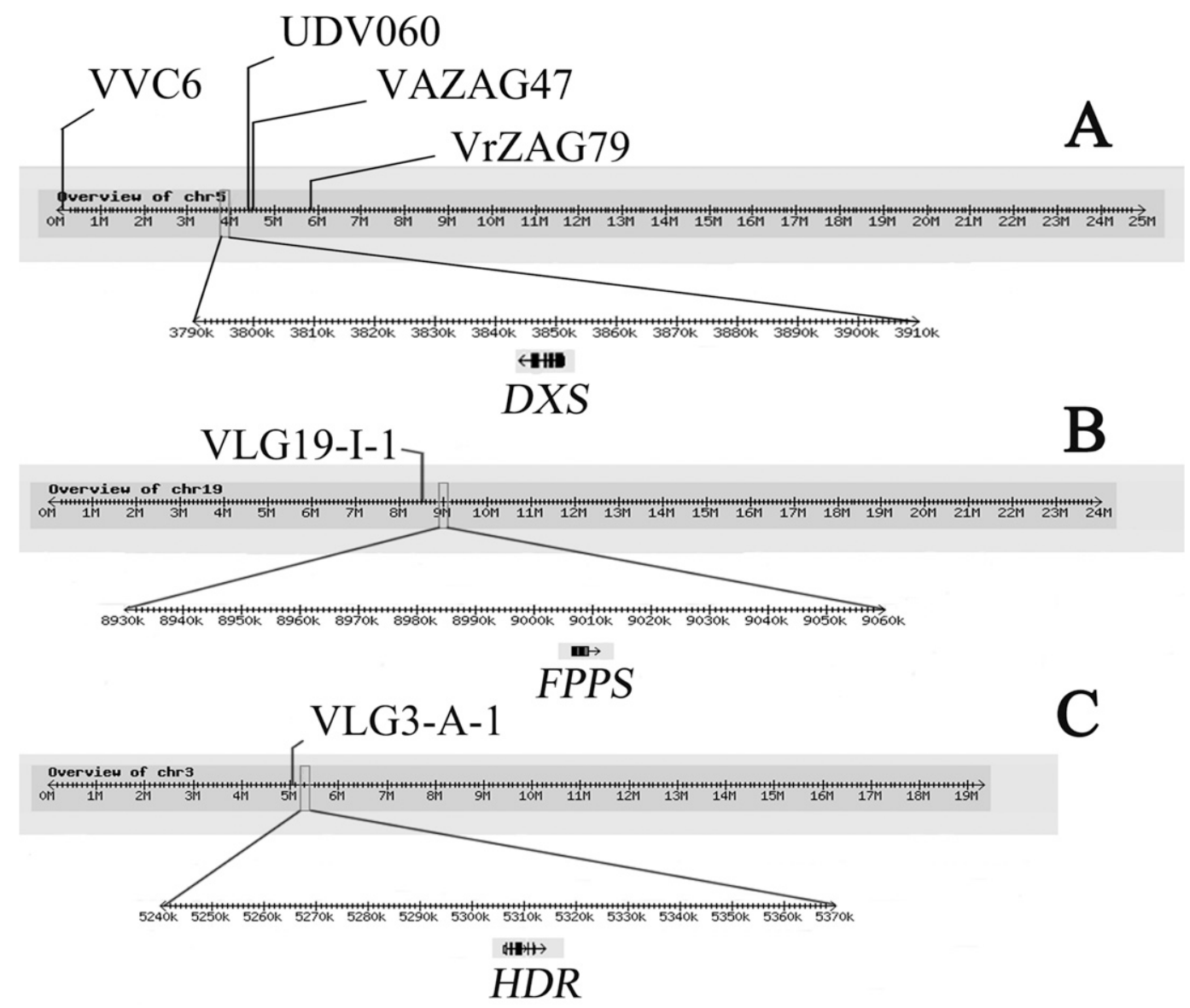

Fig. 4. Position of SSR markers and genes on the grapevine chromosome: (A) chromosome 5, (B) chromosome 19, and (C) chromosome 3. VVC6, VAZAG47, and VrZAG79 were previously found to be significantly associated with monoterpene content. UDV060, VLG19-I-1, and VLG3-A-1 were newly found to be significantly associated with monoterpene content in close proximity to the genes in this study. Deoxyxylulose phosphate synthase (DXS), Farnesyl diphosphate synthase (FPPS), and Hydroxymethylbutenyl diphosphate reductase (HDR) have been functionally catalyzed during monoterpenol biosynthesis.

supply marker candidates for marker-assisted selection of aroma compounds in grapevine.

\section{Literature Cited}

Aradhya, M.K., G.S. Dangl, B.H. Prins, J.M. Boursiquot, M.A. Walker, C.P. Meredith, and C.J. Simon. 2003. Genetic structure and differentiation in cultivated grape, Vitis vinifera L. Genet. Res. 81:179-182.

Atwell, S., Y.S. Huang, B.J. Vilhjálmsson, G. Willems, M. Horton, Y. Li, D. Meng, A. Platt, A.M. Tarone, T.T. Hu, R. Jiang, N.W. Muliyati, X. Zhang, M.A. Amer, I. Baxter, B. Brachi, J. Chory, C. Dean, M. Debieu, J. Meaux, J.R. Ecker, N. Faure, J.M. Kniskern, J.D. Jones, T. Michael, A. Nemri, F. Roux, D.E. Salt, C. Tang, M. Todesco, M.B. Traw, D. Weigel, P. Marjoram, J.O. Borevitz, J. Bergelson, and M. Nordborg. 2010. Genome-wide association study of 107 phenotypes in a common set of Arabidopsis thaliana inbred lines. Nature 465:627-631.

Barnaud, A., T. Lacombe, and A. Doligez. 2006. Linkage disequilibrium in cultivated grapevine, Vitis vinifera L. Theor. Appl. Genet. 112:708-716.

Barnaud, A., V. Laucou, P. This, T. Lacombe, and A. Doligez. 2010. Linkage disequilibrium in wild French grapevine, Vitis vinifera $\mathrm{L}$. subsp. silvestris. Heredity 104:431-437.

Battilana, J., F. Emanuelli, G. Gambino, I. Gribaudo, F. Gasperi, and P.K. Boss. 2011. Functional effect of grapevine 1-deoxy-D-xylulose5phosphate synthase substitution $\mathrm{K} 284 \mathrm{~N}$ on muscat flavour formation. J. Expt. Bot. 62:5497-5508.
Battilana, J., L. Costantini, F. Emanuelli, F. Sevini, C. Segala, S. Moser, R. Velasco, G. Versini, and M. StellaGrando. 2009. The 1-deoxy-D-xylulose 5-phosphate synthase gene co-localizes with a major QTL affecting monoterpene content in grapevine. Theor. Appl. Genet. 118:653-669.

Bohlmann, J. and C.I. Keeling. 2008. Terpenoid biomaterials. Plant J. 54:656-669.

Bradbury, P.J., Z. Zhang, E. Dallas, K. Terry, M. Casstevens, Y. Ramdo, and S.B. Edward. 2007. TASSEL: Software for association mapping of complex traits in diverse samples. Bioinformatics 23:2633-2635.

Chacón, J.L., E. García, J. Martínez, A. Mena, and P.M. Izquierdo. 2012. Comparison of aromatic composition of an endangered variety (Albilla Dorada) with other recognized aromatic varieties. Vitis $51: 15-17$.

Chang, E.H., S.M. Jung, and Y.Y. Hur. 2014. Changes in the aromatic composition of grape $\mathrm{cv}$. Cheongsoo wine depending on the degree of grape ripening. Food Sci. Biotechnol. 23:1761-1771.

Doligez, A., E. Audiot, R. Baumes, and P. This. 2006. QTLs for muscat flavour and monoterpenic odorant content in grapevine (Vitis vinifera L.). Mol. Breed. 18:109-125.

Emanuelli, F., J. Battilana, L. Costantini, L. Le Cunff, J.M. Boursiquot, P. This, and M.S. Grando. 2010. A candidate gene association study on muscat flavor in grapevine (Vitis vinifera L.). BMC Plant Biol. 10:241.

Evanno, G., S. Regnaut, and J. Goudet. 2005. Detecting the number of clusters of individuals using the software STRUCTURE: A simulation study. Mol. Ecol. 14:2611-2620. 
Forcada, C.F.I., N. Oraguzie, E. Igartua, M.A. Moreno, and Y. Gogorcena. 2013. Population structure and marker-trait associations for pomological traits in peach and nectarine cultivars. Tree Genet. Genomes 9:331-349.

Ghaste, M., L. Narduzzia, S. Carlina, U. Vrhovseka, V. Shulaevc, and F. Mattivia. 2015. Chemical composition of volatile aroma metabolites and their glycosylated precursors that can uniquely differentiate individual grape cultivars. Food Chem. 188:309-319.

Guo, W., C. Cai, C. Wang, Z. Han, X. Song, K. Wang, X. Niu, C. Wang, K. Lu, B. Shi, and T. Zhang. 2007. A microsatellite-based, gene-rich linkage map reveals genome structure, function and evolution in gossypium. Genetics 176:527-541.

Guo, Y.S., G.L. Shi, Z.D. Liu, Y.H. Zhao, X.X. Yang, J.C. Zhu, K. Li, and X.W. Guo. 2014. Using specific length amplified fragment sequencing to construct the high-density genetic map for Vitis (Vitis vinifera L.XVitis amurensis Rupr.). Front. Plant Sci. 6:393.

Hanania, U., M. Velcheva, N. Sahar, and A. Pret. 2004. An improved method for isolating high-quality DNA from Vitis vinifera nuclei. Plant Mol. Biol. Rpt. 22:173-177.

Huang, H., J. Lu, Z. Ren, W. Hunter, S.E. Dowd, and P. Dang. 2011. Mining and validating grape (Vitis L.) ESTs to develop EST-SSR markers for genotyping and mapping. Mol. Breed. 28:241-254.

Jannoo, N., L. Grivet, A. Dookun, A. Hont, and J.C. Glaszmann. 1999. Linkage disequilibrium among modern sugarcane cultivars. Theor. Appl. Genet. 99:1053-1060.

Jun, T.H., K. Van, M.Y. Kim, S.H. Lee, and D.R. Walker. 2008. Association analysis using SSR markers to find QTL for seed protein content in soybean. Euphytica 162:179-191.

Liu, K. and S.V. Muse. 2005. PowerMarker: An integrated analysis environment for genetic marker analysis. Bioinformatics 21:21282129.

Luan, F. and M. Wust. 2002. Differential incorporation of 1-deoxy-Dxylulose into (3S)-linalool and geraniol in grape berry exocarp and mesocarp. Phytochemistry 60:451-459.

Lund, S.T. and J. Bohlmann. 2006. The molecular basis for wine grape quality: A volatile subject. Science 311:804-805.

Maoz, I., D. Beno-Moualem, T. Kaplunov, E. Lewinsohn, and A. Lichter. 2016. Uneven distribution of flavour components in table grape berries. Austral. J. Grape Wine Res. 22:343-349.

Marrano, A., L. Grzeskowiak, P. Moreno sanz, S. Lorenzi, and M.L. Prazzoli. 2015. Genetic diversity and relationships in the grapevine germplasm collection from central Asia. Vitis 54:233-237.

Martin, D.M., S. Aubourg, M.B. Schouwey, L. Daviet, and M. Schalk. 2010. Functional annotation, genome organization and phylogeny of the grapevine (Vitis vinifera) terpene synthase gene family based on genome assembly, FLcDNA cloning, and enzyme assays. BMC Plant Biol. 10:226-238.
Martin, D.M., A. Chiang, S.T. Lund, and J. Bohlmann. 2012. Biosynthesis of wine aroma: Transcript profiles of hydroxymethylbutenyl diphosphate reductase, geranyl diphosphate synthase, and linalool/nerolidol synthase parallel monoterpenol glycoside accumulation in Gewurztraminer grapes. Planta 236:919-929.

Mateo, J.J. and M. Jimenez. 2000. Monoterpenes in grape juice and wines. J. Chromatography 881:557-567.

Moreno-Sanz, P., M.D. Loureiro, and B. Suárez. 2011. Microsatellite characterization of grapevine (Vitis vinifera L.) genetic diversity in Asturias (northern Spain). Sci. Hort. 129:433-440.

Myles, S., A.R. Boyko, C.L. Owens, P.J. Brown, F. Grassi, M.K. Aradhya, B. Prins, A. Reynolds, J.M. Chia, D. Ware, C.D. Bustamante, and E.S. Buckler. 2011. Genetic structure and domestication history of the grape. Proc. Natl. Acad. Sci. USA 108:3457-3458.

Nei, M. 1978. Estimation of average heterozygosity and genetic distance from a small number of individuals. Genetics 89:583-590.

Peakall, R. and P.E. Smouse. 2012. GENAlEX 6.5: Genetic analysis in Excel. Population genetic software for teaching and research an update. Bioinformatics 28:2537-2539.

Pritchard, J.K., M. Stephens, and P. Donnelly. 2000b. Inference of population structure using multilocus genotype data. Genetics 155:945-959.

Pritchard, J.K., M. Stephanes, N.A. Rosenberg, and P. Donnelly. 2000a. Association mapping in structured populations. Amer. J. Hum. Genet. 67:170-181.

Sefc, K.M., M.S. Lopes, F. Lefort, R. Botta, and K.A. Roubelakisangelakis. 2000. Microsatellite variability in grapevine varieties from different European regions and evaluation of assignment testing to assess the geographic origin of varieties. Theor. Appl. Genet. 100:498-505.

Sun, L., B.Q. Zhu, and X.R. Sunday. 2014. Terpenes biosynthesis related gene transcript profiles and terpenes accumulation of 'Alexandria' grape. Zhongguo Nong Ye Ke Xue 47:1379-1386.

Wen, J.H., H.L. Shen, and L.R. Zou. 2011. Analysis of genetic relationship among 20 Vitis germplasm resources by SSR markers. Guoshu Xuebao 28:782-786.

Wen, Y.Q., G.Y. Zhong, Y. Gao, Y.B. Lan, C.Q. Duan, and Q.H. Pan. 2015. Using the combined analysis of transcripts and metabolites to propose key genes for differential terpene accumulation across two regions. BMC Plant Biol. 15:240.

Wu, Y.W., Q.H. Pan, W.J. Qu, and C.Q. Duan. 2009. Comparison of volatile profiles of nine litchi (Litchi chinensis Sonn.) cultivars from southern China. J. Agr. Food Chem. 57:9676-9681.

Zhao, Y., H. Wang, W. Chen, and Y. Li. 2014. Genetic structure, linkage disequilibrium and association mapping of verticillium wilt resistance in elite cotton (Gossypium hirsutum L.) germplasm population. PLoS One 9:e86308. 

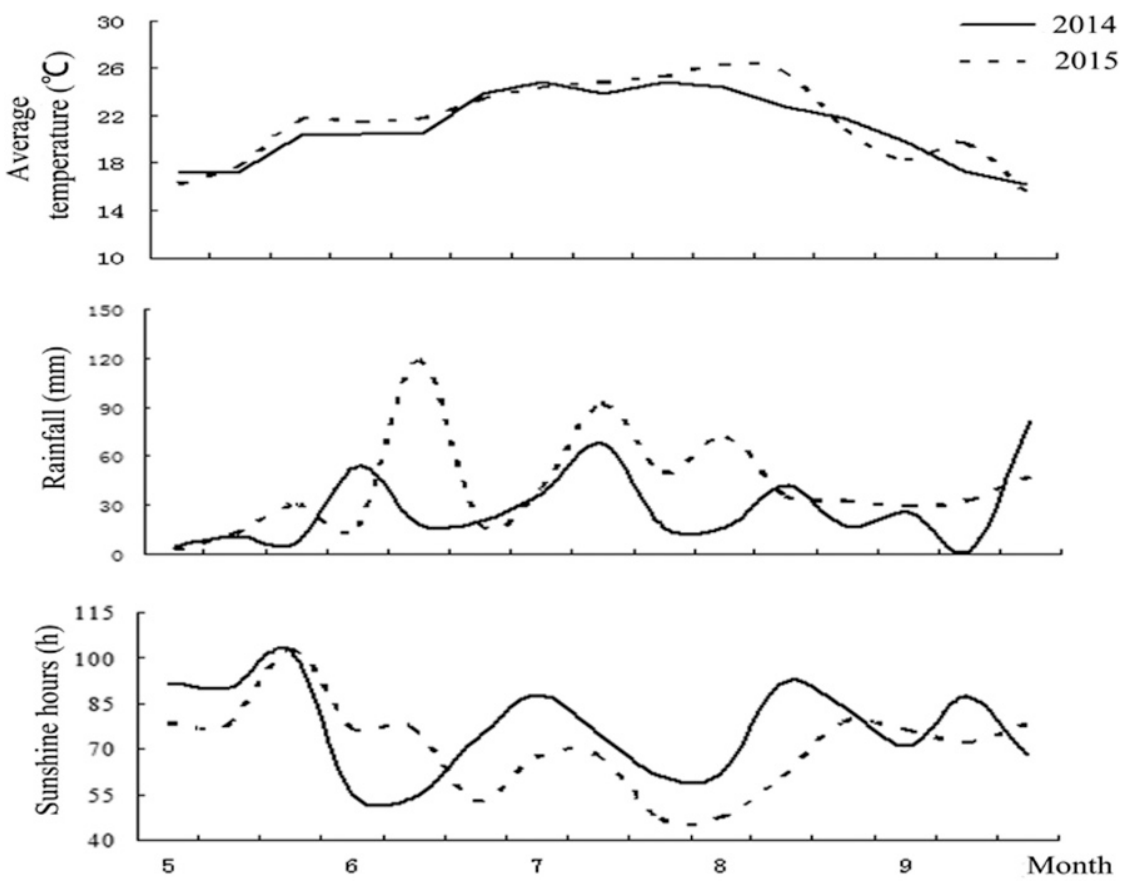

Supplemental Fig. 1. Main weather parameters of 2014 and 2015 of Shenyang county, Liaoning province, China. The weather parameters include average temperature, rainfall, and sunshine hours (data provided by China Meterological Data Sharing Service System).

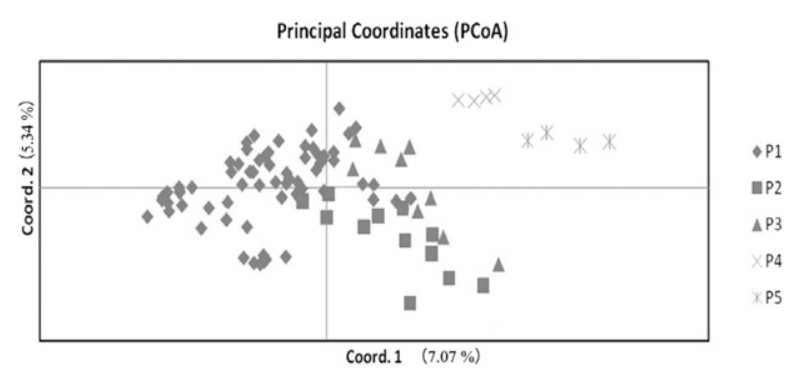

Supplemental Fig. 2. Principal coordinate analysis (PCoA) of 96 grapevine accessions. The different shapes represent the five populations based on the 187 SSR loci. The first and second principal coordinates account for $7.07 \%$ and $5.34 \%$ of the total variation, respectively.

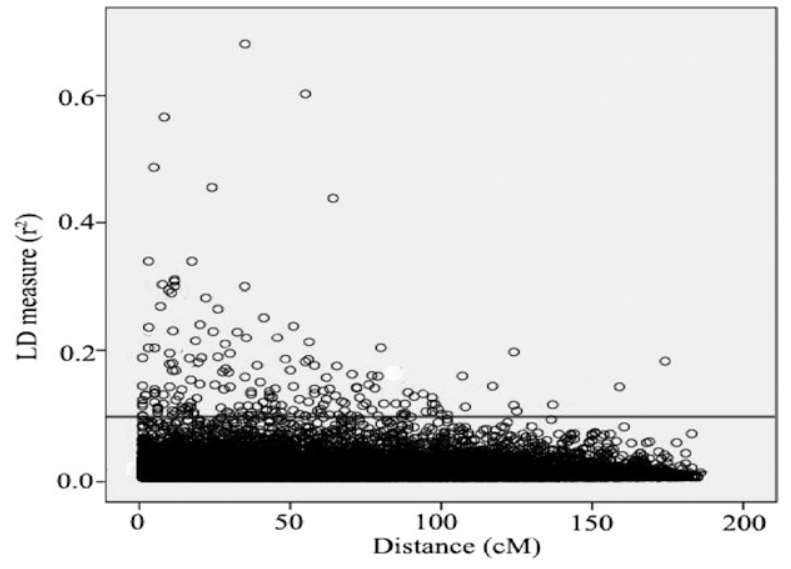

Supplemental Fig. 3. The pattern of linkage disequilibrium (LD) for 187 SSR loci indicating correlations of allele frequencies $\left(r^{2}\right)$ value against genetic distance (in cM) between all loci pairs in all 96 grapevine accessions. The horizontal line in the plot indicates $r^{2}=0.1$. 
Supplemental Table 1. Sources and cultivar type of 96 grapevines. This included five species/hybrids under the genus Vitis namely $V$. vinifera, $V$. vinifera V. labrusca, $V$. vinifera $V$. amurensis, V. amurensis, and V. labrusca.

\begin{tabular}{|c|c|c|c|c|}
\hline Code & Cultivar or line & Source $^{\mathrm{z}}$ & Cultivar type & Species \\
\hline 1 & Venus seedless & USA & Introduced & V. vinifera $V$. labrusca \\
\hline 2 & Suffolk Red & USA & Introduced & $V$. vinifera $V$. labrusca \\
\hline 3 & Centennial Seedless & USA & Introduced & V. vinifera \\
\hline 4 & Christmas Rose & USA & Introduced & V. vinifera \\
\hline 5 & Autumn Black & USA & Introduced & V. vinifera \\
\hline 6 & Red Globe & USA & Introduced & $V$. vinifera \\
\hline 7 & LN333 & USA & Introduced & $V$. vinifera $V$. labrusca \\
\hline 8 & Yatomi Rosa & JPN & Introduced & $V$. vinifera \\
\hline 9 & Emerald Seedless & USA & Introduced & V. vinifera \\
\hline 10 & Crimson Seedless & USA & Introduced & V. vinifera \\
\hline 11 & Cayuga white & USA & Introduced & V. vinifera $V$. labrusca \\
\hline 12 & Canadice Seedless & USA & Introduced & $V$. vinifera $V$. labrusca \\
\hline 13 & Tamina & ROU & Introduced & $V$. vinifera. \\
\hline 14 & Lakemont Seedless & USA & Introduced & $V$. vinifera $V$. labrusca \\
\hline 15 & Exotic & USA & Introduced & V. vinifera \\
\hline 16 & Thompson Seedless & USA & Introduced & $V$. vinifera \\
\hline 17 & Horizon & USA & Introduced & $V$. vinifera $V$. labrusca \\
\hline 18 & Autumn Seedless & USA & Introduced & $V$. vinifera \\
\hline 19 & Queenora & USA & Introduced & $V$. vinifera $V$. labrusca \\
\hline 20 & Jingzaojin & $\mathrm{CHN}$ & Synthetic & $V$. vinifera \\
\hline 21 & Muscat Hamburg & UK & Introduced & V. vinifera \\
\hline 22 & Ruby seedless & USA & Introduced & V. vinifera \\
\hline 23 & Bixiang wuhe & $\mathrm{CHN}$ & Synthetic & V. vinifera \\
\hline 24 & $87-1$ & $\mathrm{CHN}$ & Line & V. vinifera \\
\hline 25 & Zaoheibao & $\mathrm{CHN}$ & Synthetic & V. vinifera \\
\hline 26 & Victoria & ROU & Introduced & $V$. vinifera \\
\hline 27 & Zhuosexiang & $\mathrm{CHN}$ & Synthetic & $V$. vinifera $V$. labrusca \\
\hline 28 & Italia & ITA & Introduced & $V$. vinifera \\
\hline 29 & Rizamat & RUS & Introduced & V. vinifera \\
\hline 30 & Red Balad & $\mathrm{CHN}$ & Synthetic & V. vinifera \\
\hline 31 & Flame seedless & USA & Introduced & V. vinifera \\
\hline 32 & Brown Seedless & USA & Introduced & $V$. vinifera $V$. labrusca \\
\hline 33 & Remaily Seedless & USA & Introduced & $V$. vinifera $V$. labrusca \\
\hline 34 & Jingyu & $\mathrm{CHN}$ & Synthetic & V. vinifera \\
\hline 35 & Mars seedless & USA & Introduced & $V$. vinifera $V$. labrusca \\
\hline 36 & Skyler & USA & Introduced & $V$. vinifera $V$. labrusca \\
\hline 37 & $01-36$ & $\mathrm{CHN}$ & Line & $V$. vinifera \\
\hline 38 & Shine Muscat & JPN & Introduced & $V$. vinifera $V$. labrusca \\
\hline 39 & $4-355$ & $\mathrm{CHN}$ & Line & $V$. vinifera $V$. labrusca \\
\hline 40 & D-419 & $\mathrm{CHN}$ & Line & V. vinifera \\
\hline 41 & D-15 & $\mathrm{CHN}$ & Line & $V$. vinifera \\
\hline 42 & $4-162$ & $\mathrm{CHN}$ & Line & $V$. vinifera $V$. labrusca \\
\hline 43 & Black Balad & JPN & Introduced & $V$. vinifera \\
\hline 44 & Shennongjinhuanghou & $\mathrm{CHN}$ & Synthetic & $V$. vinifera \\
\hline 45 & $4-342$ & $\mathrm{CHN}$ & Line & $V$. vinifera $V$. labrusca \\
\hline 46 & $14-10 \mathrm{~A}$ & $\mathrm{CHN}$ & Line & V. vinifera \\
\hline 47 & $1-344$ & $\mathrm{CHN}$ & Line & $V$. vinifera $V$. amurensis \\
\hline 48 & $1-243$ & $\mathrm{CHN}$ & Line & $V$. vinifera $V$. amurensis \\
\hline 49 & $1-260$ & $\mathrm{CHN}$ & Line & $V$. vinifera $V$. amurensis \\
\hline 50 & $1-357$ & $\mathrm{CHN}$ & Line & $V$. vinifera $V$. amurensis \\
\hline 51 & Zaoxiameigui & $\mathrm{CHN}$ & Synthetic & $V$. vinifera \\
\hline 52 & $12-16$ & $\mathrm{CHN}$ & Line & V. vinifera \\
\hline 53 & Beibinghong & $\mathrm{CHN}$ & Synthetic & $V$. vinifera $V$. amurensis \\
\hline 54 & Shennongcuifeng & $\mathrm{CHN}$ & Synthetic & V. vinifera \\
\hline 55 & $14-52$ & $\mathrm{CHN}$ & Line & V. vinifera \\
\hline 56 & Jingxiu & $\mathrm{CHN}$ & Synthetic & V. vinifera \\
\hline 57 & D-341 & $\mathrm{CHN}$ & Line & V. vinifera \\
\hline
\end{tabular}


Supplemental Table 1. Continued.

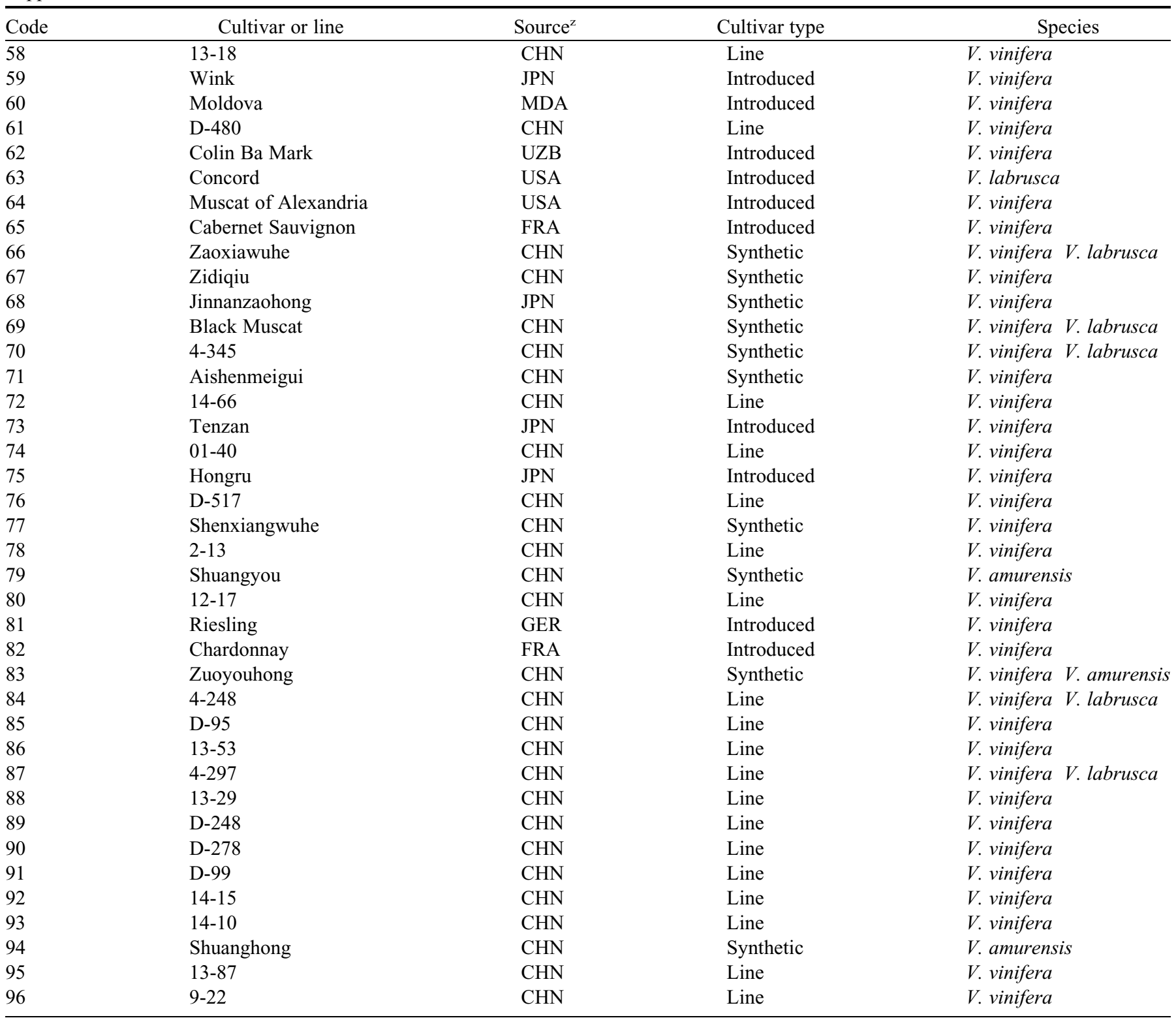

$\overline{{ }^{\mathrm{z}} \mathrm{CHN}}=$ China; FRA $=$ France; GER = Germany; ITA = Italy; JPN = Japan; MDA = Moldova; ROU = Romania; RUS = Russian; UK = United Kingdom; USA = United States of America; UZB = Uzbekistan. 
Supplemental Table 2. We selected 187 pairs of SSR primers with clear polymorphic bands for use in this study. These primers may contribute to genetic diversity and association study of aromatics in grapevine. The information of linkage group, position, and sequence for the 187 SSR primers is listed in the table.

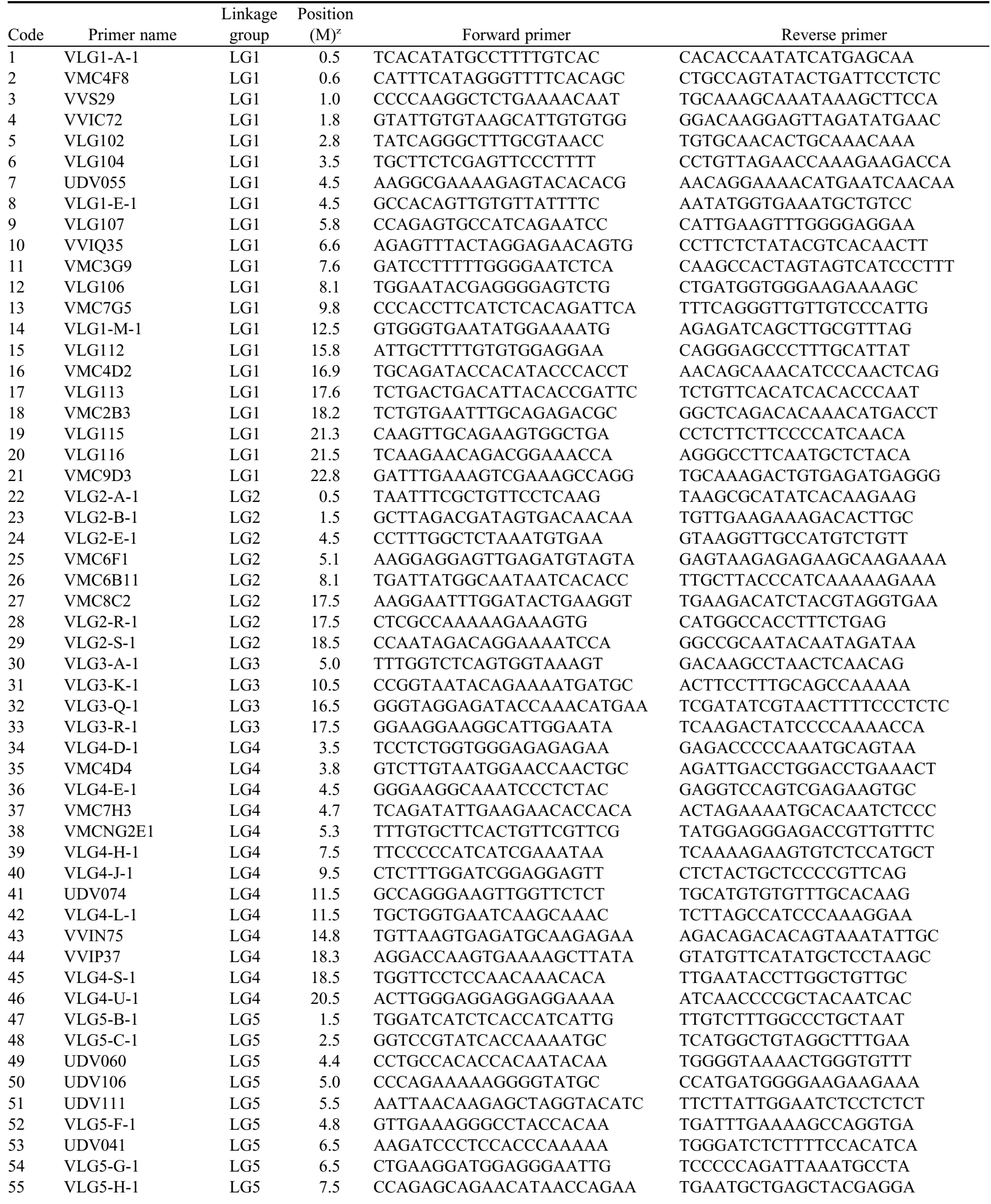


Supplemental Table 2. Continued.

\begin{tabular}{|c|c|c|c|c|c|}
\hline Code & Primer name & $\begin{array}{l}\text { Linkage } \\
\text { group }\end{array}$ & $\begin{array}{c}\text { Position } \\
(\mathrm{M})^{\mathrm{z}}\end{array}$ & Forward primer & Reverse primer \\
\hline$\overline{56}$ & UDV053 & LG5 & 8.5 & GTTGGTGGCTTTCTTTTTGC & GGGAGAAAAAGGCATGGATA \\
\hline 57 & VLG5-J-1 & LG5 & 9.5 & TTGGGATTGGCATCTTCAAT & GGAGAAATTTGGCTAAGAAAGG \\
\hline 59 & VVIN33 & LG5 & 11.3 & TGCCAAAGCAAGTATCAACATG & ATTTTGATCCCACCTAACTCTG \\
\hline 60 & VMC3C7 & LG5 & 12.3 & AATTTGGCTAAGAAAGGA & AATATTCAGAAAATTTGTGTC \\
\hline 63 & VLG5-O-1 & LG5 & 14.5 & GAGTGCTTCGGGTTTAATGG & AAAGGGACAAGTCAATGCAGA \\
\hline 64 & VMC16D4 & LG5 & 16.5 & TAGAATACACAGGCCATATACAA & GGTTAGGATGCATATAGAAGAAG \\
\hline 65 & VLG5-T-1 & LG5 & 19.5 & CACTCCTGCCCATTTACCAC & CGCTTCGGAATCGATCTTAG \\
\hline 66 & VLG5-U-1 & LG5 & 20.5 & CCCCAACACACAAACAAAAC & TTGTCGGATGGTTCTTGACA \\
\hline 67 & UDV064 & LG5 & 22.3 & TCTGCGAGTATTTGCAACC & CAACCGTGGCTAGCAATTTT \\
\hline 68 & VMC2E9 & LG5 & 23.1 & GTTGTTTCTCTCCCATTCCTAA & GACATTTTTGTTGTAGGGGTTG \\
\hline 73 & VLG6-E-1 & LG6 & 4.5 & GGATGCATAAATAATGGGGTCA & TTGTTGCAAAACCATGCCTA \\
\hline 74 & VMC2H9 & LG6 & 5.9 & AAGCAAAGCAGACCACAACG & CCCAGCTCCTTAGCTCCTCA \\
\hline 75 & VLG6-G-1 & LG6 & 6.5 & CCCACAAGCTCTATCCCTCA & CCGCCCCTTTTATTTCATTT \\
\hline 76 & VLG6-O-1 & LG6 & 14.5 & TTTACCCTACTACAAGGCTTTC & TCTGGGCTTCCCCTATCTTT \\
\hline 77 & VLG6-P-1 & LG6 & 15.5 & CATGGTCCAACAGCCATTTA & TGTGCTATCACACCCCTTCA \\
\hline 78 & VMC3A8 & LG6 & 16.5 & ACCATGAGATCAAATTGGAACA & TGAAGCTGGAAAAGAATAGAAA \\
\hline 79 & VLG6-R-1 & LG6 & 17.5 & TGGGGAGGACTTCTCATGTT & TCTGGTGTGTGTTACCTGGA \\
\hline 80 & VMCNG4B9 & LG6 & 18.5 & CTGGGGAGCATATACACATACCAG & СТСТСТСТTCCCGATAGCCACC \\
\hline 81 & VLG7-C-1 & LG7 & 2.5 & GGTAGCATCTTTTCATTCCCTA & ATGCTTCTTTTCCACGGTTG \\
\hline 82 & VVIB22 & LG7 & 3.1 & СССТССААТСТАСАТССАTGAA & CAGTGTGTTTCTTGATGGTCCA \\
\hline 83 & UDV011 & LG7 & 3.1 & TTTATGGCAACCCTCCAATC & TTGATGGTCCACTGGAACTG \\
\hline 91 & VLG7-V-1 & LG7 & 21.5 & GCTTGAGGCTTGGAAAACAG & GGCAGGATATTCATGGTTGG \\
\hline 92 & VLG7-Z-1 & LG7 & 25.5 & AACCCAAAAGCCTCAAAAGC & GAGCAATGAGTGCTTCTTCTTG \\
\hline 93 & $\mathrm{VMC} 2 \mathrm{~F} 12$ & LG8 & 0.5 & GGATTGGGCTCAGAAATAGGCT & TTCCAGAACACAGGCCACATAC \\
\hline 94 & UDV075 & LG8 & 2.5 & TCACCTGTAGACCCAACAACC & GCCTCAGACCAAAGGAATGA \\
\hline 95 & VVS4 & LG8 & 5.6 & CCATCAGTGATAAAACCTAATGCC & CCCACCTTGCCCTTAGATGTTA \\
\hline 96 & VMCNG-2H2-2 & LG8 & 7.2 & CCAAGTCCACGTTTTTGTTT & CTACTACACTТCACСТCAАTTATG \\
\hline 97 & VVIM07 & LG8 & 10.7 & TGGTGTCAACATTCCTTACAAG & TTATTACATGGATAGGCACTCA \\
\hline 98 & VMC1E8 & LG8 & 11.2 & CAGCGAGCTCTTGATTTATTGT & GATCATAGCTTCAACGGCTTTT \\
\hline 99 & VMC3F8 & LG8 & 15.3 & GCAATATGGACACTAGGATCAAA & AGAAATCAGCATATCCAACAACA \\
\hline 100 & VMC3C9 & LG8 & 17.5 & ATAAAATGGAATTAAGGGGGGA & CAAACGCTAGATACCATGGAGA \\
\hline 101 & VMCNG2B6 & LG8 & 21.5 & GCCACAATTGGTGGATTTTGTCTTA & ATTTGGAAGGTATGAAGCACGAGGT \\
\hline 102 & VMC6D12 & LG9 & 4.0 & СТСТСТTTTCCGAAATTGGGGT & ATTTTCCCTGGAAACAAAGTGG \\
\hline 103 & VVIQ66 & LG9 & 10.8 & CTTGCAGTGCTTTCAACAATGA & ACCAATATGATGACTTTAGCCA \\
\hline 104 & VMC2D9 & LG9 & 19.0 & TGAATTCCGAATTGGGTCT & TCAACCCTCGTCTTTAGTC \\
\hline 105 & VMC3H5 & LG9 & 20.0 & CATGTAGGTGTAGCTTACATTTC & GACACAAGACTCTATTCCTTCAA \\
\hline 106 & VVIQ52 & LG9 & 21.5 & TAAAAGGATGGTAGATGACAGA & ACAGGAAAGTGTTCAATGGTTA \\
\hline 107 & UDV073 & LG10 & 1.2 & ACCATCCTGCAAAAAGAAAA & СССТСТТСССССТСТТТСТА \\
\hline 108 & VVIR21 & LG10 & 3.6 & TTТСССТТСТСАСТСАATGATG & GAAAAGAAAACAGTGTATCCCC \\
\hline 109 & VMC8D3 & LG10 & 6.0 & TGGCAAGACACAATAAAACAG & ATAGAGTCCTGCAAATCCAAGA \\
\hline 110 & VVIN78 & LG10 & 8.5 & TAAAGGACCCATCTCAATGTTT & ACTGAGTATGGTGAGTATTGAT \\
\hline 111 & UDV063 & LG10 & 11.9 & CAAACTGCCCTTCCTTTTTG & TTGCATATGCCACAAGTGATT \\
\hline
\end{tabular}

Continued next page 
Supplemental Table 2. Continued.

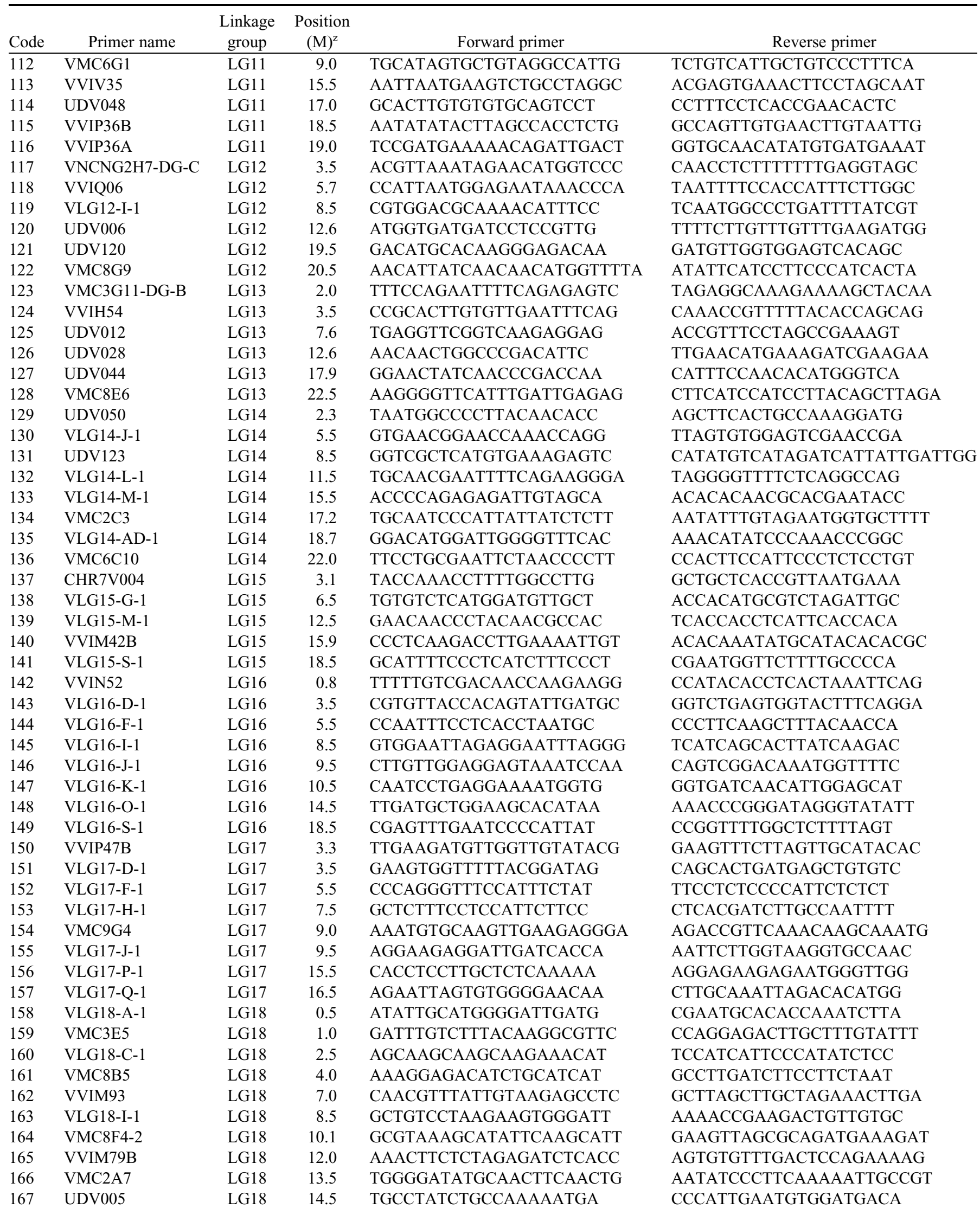

Continued next page 
Supplemental Table 2. Continued.

\begin{tabular}{lllrll}
\hline & & $\begin{array}{c}\text { Linkage } \\
\text { group }\end{array}$ & $\begin{array}{c}\text { Position } \\
(\mathrm{M})^{\mathrm{z}}\end{array}$ & \multicolumn{1}{c}{ Forward primer } & \multicolumn{1}{c}{ Reverse primer } \\
\hline 168 & VLG18-O-1 & LG18 & 14.5 & TCCCACATCGGTTAAGAAAA & TTGGTTCCCTCCTGTGTAAA \\
169 & VLG18-P-1 & LG18 & 15.5 & GGCGCTTTGGTAATGTATGA & CAACAATTGGCTGAGAGCTT \\
170 & VLG18-R-1 & LG18 & 17.5 & GATGCAACCACATCCTCTTC & AAAAAGCCACCCAAGGTAAC \\
171 & VLG18-S-1 & LG18 & 18.5 & TTGTGTTGCCATTTCACTGT & TATTCCCGGAAAAAGAAACC \\
172 & VLG18-W-1 & LG18 & 22.5 & AAAAATGCGTCGTTGTGG & TCCCCAACAATTCTCCATTA \\
173 & VVIP17A & LG19 & 0.2 & TTGGATCCATCACTCTTGTTC & TTGGTTGAGGGAAAAAGGAAAG \\
174 & VLG19-B-1 & LG19 & 1.5 & TTTTCACCATTCACTCCTCAG & CCTAGAATTCATCCTCATAGGTCT \\
175 & VLG19-C-1 & LG19 & 2.5 & GGACATAGCTAGGGCATTCA & GGTAATGAATCTGCCCAGTG \\
176 & VLG19-D-1 & LG19 & 3.5 & TCTGGAACCTAAACCCCAAT & TCCTAACACAAGGGTGCATT \\
177 & VMC5D11 & LG19 & 5.0 & CTTCCACAATCACCAAATCACA & GAAATGAATGGGAAGAGACACTG \\
178 & VLG19-H-1 & LG19 & 5.5 & CAACCTGTTTGTTCCTTTGG & GAACCTCCCTTCACTCCACT \\
179 & VMC6C7 & LG19 & 8.5 & CCTTATCTTATCCCTGTCCTGA & AGCTTCTGGGTTGGCTATG \\
180 & VLG19-I-1 & LG19 & 8.5 & ACATATATCCGAAAGTGTGGGGC & CTTAAAGCTTGAAGCTTTTGGTGC \\
181 & VLG19-L-1 & LG19 & 11.5 & GACTTGTGTTAAAGTGTTCTACCC & ATTCACACCCATCCATGTTC \\
182 & VLG19-N-1 & LG19 & 13.5 & TTGAAAGAGGGCATTCAAAG & CCTCATTGTCATCCCTATGC \\
183 & UDV127 & LG19 & 17.8 & CGTCAATCGCTTGTAATCTGC & TGAGCATTTTGCTCCTTCATT \\
184 & VLG19-S-1 & LG19 & 18.5 & CAGAGTCCATCCCATCATGT & CACACCAATCTTGCTTTTCC \\
185 & VMC5A10 & LG19 & 21.0 & GTAAAGAATAAATGGAGAGGGG & CAGTTGAGGAAAGGAAGGATAG \\
186 & VLG19-W-1 & LG19 & 22.5 & TGAGATCAACATGGGCAAAC & GCCAAATTGTGTTTGATGGT \\
187 & VMC7B1 & LG19 & 23.0 & GTAAAGAATAAATGGAGAGGGG & CAGTTGAGGAAAGGAAGGATAG \\
\hline
\end{tabular}

${ }^{\mathrm{z}}$ Chromosome location of primers. 
Supplemental Table 3. Variability parameters of the 187 SSR loci and population-genetic statistics for 96 grapevine cultivars. The statistics of SSR markers were estimated using PowerMarker [version 3.25 (Guo et al., 2007)].

\begin{tabular}{|c|c|c|c|c|c|c|c|c|c|}
\hline Marker & $\mathrm{SS}^{\mathrm{z}}$ & $\mathrm{NO}$ & MA & $\mathrm{NG}$ & NA & $\overline{\mathrm{AV}}$ & GD & $\mathrm{HE}$ & $\overline{\mathrm{PIC}}$ \\
\hline VMC4F8 & 96 & 96 & 0.93 & 4 & 3 & 1.00 & 0.14 & 0.10 & 0.13 \\
\hline VVIQ35 & 96 & 89 & 0.56 & 6 & 3 & 0.93 & 0.57 & 0.25 & 0.50 \\
\hline VMC3G9 & 96 & 89 & 0.89 & 6 & 4 & 0.93 & 0.21 & 0.08 & 0.20 \\
\hline VMC7G5 & 96 & 96 & 0.46 & 7 & 5 & 1.00 & 0.57 & 0.60 & 0.48 \\
\hline VMC4D2 & 96 & 96 & 0.34 & 20 & 8 & 1.00 & 0.78 & 0.75 & 0.75 \\
\hline VMC2B3 & 96 & 96 & 0.98 & 3 & 3 & 1.00 & 0.03 & 0.03 & 0.03 \\
\hline VMC9D3 & 96 & 96 & 0.91 & 8 & 7 & 1.00 & 0.18 & 0.17 & 0.17 \\
\hline VMC8C2 & 96 & 94 & 0.31 & 24 & 7 & 0.98 & 0.80 & 0.78 & 0.77 \\
\hline VMC6B11 & 96 & 91 & 0.71 & 15 & 10 & 0.95 & 0.48 & 0.37 & 0.46 \\
\hline VMC6F1 & 96 & 92 & 0.27 & 32 & 12 & 0.96 & 0.83 & 0.60 & 0.81 \\
\hline VMC2E9 & 96 & 96 & 0.64 & 15 & 7 & 1.00 & 0.56 & 0.44 & 0.53 \\
\hline VMC4D4 & 96 & 94 & 0.48 & 11 & 8 & 0.98 & 0.61 & 0.62 & 0.53 \\
\hline VMC7H3 & 96 & 94 & 0.70 & 16 & 7 & 0.98 & 0.49 & 0.38 & 0.46 \\
\hline VMCNG2E1 & 96 & 96 & 0.44 & 12 & 5 & 1.00 & 0.68 & 0.56 & 0.63 \\
\hline VVIN75 & 96 & 96 & 0.30 & 20 & 8 & 1.00 & 0.77 & 0.60 & 0.74 \\
\hline VVIP37 & 96 & 93 & 0.39 & 17 & 7 & 0.97 & 0.75 & 0.37 & 0.72 \\
\hline VMC3C7 & 96 & 91 & 0.46 & 13 & 7 & 0.95 & 0.68 & 0.57 & 0.63 \\
\hline VMC2H9 & 96 & 82 & 0.72 & 5 & 3 & 0.85 & 0.41 & 0.32 & 0.34 \\
\hline VVIP72 & 96 & 76 & 0.42 & 23 & 9 & 0.79 & 0.77 & 0.34 & 0.75 \\
\hline VVIB22 & 96 & 95 & 0.51 & 11 & 6 & 0.99 & 0.64 & 0.62 & 0.58 \\
\hline VVIV04 & 96 & 94 & 0.49 & 16 & 7 & 0.98 & 0.69 & 0.60 & 0.65 \\
\hline VMC2F12 & 96 & 96 & 0.31 & 18 & 9 & 1.00 & 0.75 & 0.55 & 0.71 \\
\hline VMCNG2H2-2 & 96 & 96 & 0.67 & 6 & 5 & 1.00 & 0.50 & 0.57 & 0.46 \\
\hline VVS4 & 96 & 83 & 0.31 & 15 & 10 & 0.86 & 0.78 & 0.67 & 0.75 \\
\hline VVIM07 & 96 & 92 & 0.84 & 7 & 6 & 0.96 & 0.28 & 0.18 & 0.26 \\
\hline VMCNG2B6 & 96 & 96 & 0.53 & 12 & 6 & 1.00 & 0.64 & 0.27 & 0.59 \\
\hline VMC6D12 & 96 & 93 & 0.44 & 13 & 8 & 0.97 & 0.65 & 0.39 & 0.59 \\
\hline VVIQ66 & 96 & 74 & 0.57 & 11 & 5 & 0.77 & 0.61 & 0.39 & 0.57 \\
\hline VMC2D9 & 96 & 85 & 0.49 & 8 & 4 & 0.89 & 0.65 & 0.22 & 0.59 \\
\hline VVIQ52 & 96 & 96 & 0.29 & 25 & 9 & 1.00 & 0.82 & 0.58 & 0.80 \\
\hline VMC8D3 & 96 & 96 & 0.63 & 18 & 10 & 1.00 & 0.58 & 0.43 & 0.56 \\
\hline VVIN78 & 96 & 96 & 0.67 & 11 & 6 & 1.00 & 0.51 & 0.27 & 0.47 \\
\hline VMC6G1 & 96 & 88 & 0.62 & 10 & 7 & 0.92 & 0.52 & 0.53 & 0.45 \\
\hline VVIV35 & 96 & 96 & 0.47 & 16 & 6 & 1.00 & 0.67 & 0.54 & 0.63 \\
\hline VMC8G9 & 96 & 96 & 0.45 & 10 & 5 & 1.00 & 0.64 & 0.44 & 0.57 \\
\hline VVIH54 & 96 & 95 & 0.71 & 11 & 7 & 0.99 & 0.46 & 0.37 & 0.42 \\
\hline VMC6C10 & 96 & 96 & 0.64 & 21 & 10 & 1.00 & 0.55 & 0.46 & 0.51 \\
\hline VVIN52 & 96 & 95 & 0.69 & 8 & 6 & 0.99 & 0.47 & 0.06 & 0.42 \\
\hline VMC9G4 & 96 & 90 & 0.42 & 13 & 7 & 0.94 & 0.71 & 0.31 & 0.67 \\
\hline VMC3E5 & 96 & 94 & 0.45 & 13 & 8 & 0.98 & 0.65 & 0.61 & 0.59 \\
\hline VMC8B5 & 96 & 95 & 0.51 & 11 & 6 & 0.99 & 0.64 & 0.62 & 0.58 \\
\hline VVIM93 & 96 & 94 & 0.49 & 16 & 7 & 0.98 & 0.69 & 0.60 & 0.65 \\
\hline VMC5A10 & 96 & 96 & 0.31 & 18 & 9 & 1.00 & 0.75 & 0.55 & 0.71 \\
\hline VMC7B1 & 96 & 90 & 0.41 & 6 & 3 & 0.94 & 0.65 & 0.61 & 0.57 \\
\hline VVS29 & 96 & 85 & 0.72 & 3 & 2 & 0.89 & 0.40 & 0.22 & 0.32 \\
\hline UDV055 & 96 & 96 & 0.67 & 6 & 5 & 1.00 & 0.50 & 0.57 & 0.46 \\
\hline VVIV21 & 96 & 83 & 0.31 & 15 & 10 & 0.86 & 0.78 & 0.67 & 0.75 \\
\hline UDV106 & 96 & 92 & 0.86 & 5 & 4 & 0.96 & 0.25 & 0.15 & 0.23 \\
\hline VMCNG4B9 & 96 & 94 & 0.68 & 14 & 8 & 0.98 & 0.52 & 0.26 & 0.49 \\
\hline UDV090 & 96 & 95 & 0.47 & 16 & 8 & 0.99 & 0.66 & 0.38 & 0.61 \\
\hline VMC5H5 & 96 & 84 & 0.63 & 10 & 7 & 0.88 & 0.56 & 0.26 & 0.52 \\
\hline UDV075 & 96 & 93 & 0.56 & 9 & 6 & 0.97 & 0.60 & 0.49 & 0.54 \\
\hline VMC1E8 & 96 & 95 & 0.69 & 6 & 6 & 0.99 & 0.49 & 0.62 & 0.45 \\
\hline VMC3F8 & 96 & 87 & 0.45 & 20 & 10 & 0.91 & 0.72 & 0.21 & 0.69 \\
\hline VMC3H5 & 96 & 96 & 0.35 & 25 & 11 & 1.00 & 0.77 & 0.67 & 0.73 \\
\hline UDV073 & 96 & 96 & 0.51 & 7 & 4 & 1.00 & 0.61 & 0.67 & 0.54 \\
\hline VVIR21 & 96 & 83 & 0.33 & 16 & 6 & 0.86 & 0.78 & 0.55 & 0.74 \\
\hline
\end{tabular}


Supplemental Table 3. Continued.

\begin{tabular}{|c|c|c|c|c|c|c|c|c|c|}
\hline Marker & $\mathrm{SS}^{\mathrm{z}}$ & NO & MA & NG & NA & AV & GD & $\mathrm{HE}$ & PIC \\
\hline UDV063 & 96 & 86 & 0.37 & 16 & 9 & 0.90 & 0.78 & 0.58 & 0.75 \\
\hline VNCNG2H7-DG-C & 96 & 94 & 0.44 & 13 & 6 & 0.98 & 0.71 & 0.27 & 0.67 \\
\hline VMC3G11-DG-B & 96 & 86 & 0.59 & 13 & 6 & 0.90 & 0.59 & 0.57 & 0.54 \\
\hline VMC8E6 & 96 & 90 & 0.88 & 6 & 4 & 0.94 & 0.21 & 0.17 & 0.20 \\
\hline UDV050 & 96 & 87 & 0.79 & 7 & 4 & 0.91 & 0.35 & 0.31 & 0.33 \\
\hline VMC8F4-2 & 96 & 90 & 0.62 & 11 & 5 & 0.94 & 0.58 & 0.47 & 0.55 \\
\hline VMC2A7 & 96 & 96 & 0.53 & 8 & 5 & 1.00 & 0.57 & 0.66 & 0.49 \\
\hline VMC5D11 & 96 & 87 & 0.93 & 5 & 3 & 0.91 & 0.13 & 0.03 & 0.12 \\
\hline VMC6C7 & 96 & 88 & 0.46 & 12 & 5 & 0.92 & 0.68 & 0.84 & 0.63 \\
\hline UDV127 & 96 & 86 & 0.44 & 17 & 6 & 0.90 & 0.72 & 0.67 & 0.68 \\
\hline VVIC72 & 96 & 91 & 0.43 & 17 & 7 & 0.95 & 0.73 & 0.70 & 0.69 \\
\hline VMC5F2 & 96 & 54 & 0.79 & 3 & 2 & 0.56 & 0.34 & 0.02 & 0.28 \\
\hline UDV064 & 96 & 93 & 0.43 & 15 & 7 & 0.97 & 0.72 & 0.66 & 0.68 \\
\hline VMC16D4 & 96 & 86 & 0.49 & 13 & 6 & 0.90 & 0.67 & 0.38 & 0.63 \\
\hline VVIN33 & 96 & 91 & 0.47 & 16 & 6 & 0.95 & 0.70 & 0.49 & 0.66 \\
\hline UDV053 & 96 & 92 & 0.38 & 14 & 5 & 0.96 & 0.70 & 0.62 & 0.65 \\
\hline UDVO41 & 96 & 82 & 0.52 & 14 & 5 & 0.85 & 0.65 & 0.50 & 0.61 \\
\hline UDV060 & 96 & 95 & 0.69 & 3 & 2 & 0.99 & 0.42 & 0.23 & 0.33 \\
\hline VMC3A8 & 96 & 61 & 0.43 & 8 & 5 & 0.64 & 0.67 & 0.15 & 0.61 \\
\hline UDV011 & 96 & 74 & 0.53 & 13 & 6 & 0.77 & 0.64 & 0.65 & 0.60 \\
\hline VVIV36 & 96 & 87 & 0.44 & 13 & 5 & 0.91 & 0.68 & 0.59 & 0.63 \\
\hline VMC3C9 & 96 & 93 & 0.58 & 12 & 6 & 0.97 & 0.62 & 0.57 & 0.58 \\
\hline UDV048 & 96 & 57 & 0.38 & 10 & 6 & 0.59 & 0.69 & 0.32 & 0.63 \\
\hline VMC2C3 & 96 & 96 & 0.69 & 10 & 5 & 1.00 & 0.49 & 0.39 & 0.45 \\
\hline VVIM42B & 96 & 95 & 0.34 & 26 & 9 & 0.99 & 0.81 & 0.78 & 0.79 \\
\hline VVIM79B & 96 & 91 & 0.39 & 6 & 4 & 0.95 & 0.66 & 0.19 & 0.58 \\
\hline VVIP17A & 96 & 95 & 0.56 & 5 & 3 & 0.99 & 0.54 & 0.49 & 0.45 \\
\hline VVIP36A & 96 & 96 & 0.46 & 9 & 6 & 1.00 & 0.66 & 0.63 & 0.60 \\
\hline VVIP36B & 96 & 95 & 0.34 & 26 & 8 & 0.99 & 0.80 & 0.83 & 0.77 \\
\hline VVIP47B & 96 & 91 & 0.53 & 14 & 6 & 0.95 & 0.65 & 0.43 & 0.61 \\
\hline VVIQ06 & 96 & 94 & 0.33 & 23 & 10 & 0.98 & 0.78 & 0.43 & 0.76 \\
\hline VVIQ17 & 96 & 72 & 0.40 & 10 & 5 & 0.75 & 0.69 & 0.44 & 0.63 \\
\hline UDV005 & 96 & 96 & 0.49 & 19 & 8 & 1.00 & 0.69 & 0.52 & 0.65 \\
\hline UDV006 & 96 & 96 & 0.94 & 3 & 2 & 1.00 & 0.12 & 0.06 & 0.11 \\
\hline UDV012 & 96 & 95 & 0.57 & 16 & 8 & 0.99 & 0.64 & 0.71 & 0.61 \\
\hline UDV028 & 96 & 88 & 0.78 & 6 & 4 & 0.92 & 0.37 & 0.28 & 0.34 \\
\hline UDV044 & 96 & 88 & 0.65 & 5 & 4 & 0.92 & 0.48 & 0.01 & 0.41 \\
\hline UDV074 & 96 & 94 & 0.48 & 10 & 4 & 0.98 & 0.59 & 0.52 & 0.51 \\
\hline UDV111 & 96 & 81 & 0.52 & 11 & 6 & 0.84 & 0.65 & 0.47 & 0.61 \\
\hline UDV120 & 96 & 90 & 0.33 & 16 & 10 & 0.94 & 0.79 & 0.11 & 0.77 \\
\hline UDV123 & 96 & 94 & 0.70 & 6 & 4 & 0.98 & 0.44 & 0.04 & 0.38 \\
\hline CHR7V004 & 96 & 95 & 0.47 & 12 & 6 & 0.99 & 0.61 & 0.57 & 0.53 \\
\hline VLG102 & 96 & 89 & 0.29 & 18 & 7 & 0.93 & 0.79 & 0.52 & 0.76 \\
\hline VLG104 & 96 & 93 & 0.35 & 10 & 6 & 0.97 & 0.72 & 0.19 & 0.67 \\
\hline VLG106 & 96 & 96 & 0.55 & 7 & 4 & 1.00 & 0.59 & 0.61 & 0.52 \\
\hline VLG107 & 96 & 96 & 0.57 & 2 & 2 & 1.00 & 0.49 & 0.86 & 0.37 \\
\hline VLG112 & 96 & 91 & 0.66 & 10 & 6 & 0.95 & 0.49 & 0.16 & 0.42 \\
\hline VLG113 & 96 & 87 & 0.48 & 6 & 4 & 0.91 & 0.64 & 0.26 & 0.57 \\
\hline VLG115 & 96 & 86 & 0.69 & 9 & 6 & 0.90 & 0.49 & 0.13 & 0.47 \\
\hline VLG116 & 96 & 93 & 0.54 & 13 & 7 & 0.97 & 0.64 & 0.39 & 0.59 \\
\hline VLG1-A-1 & 96 & 94 & 0.51 & 7 & 4 & 0.98 & 0.62 & 0.53 & 0.55 \\
\hline VLG1-E-1 & 96 & 90 & 0.30 & 19 & 7 & 0.94 & 0.79 & 0.78 & 0.76 \\
\hline VLG1-M-1 & 96 & 84 & 0.48 & 10 & 5 & 0.88 & 0.61 & 0.44 & 0.53 \\
\hline VLG2-A-1 & 96 & 96 & 0.64 & 13 & 5 & 1.00 & 0.56 & 0.56 & 0.53 \\
\hline VLG2-B-1 & 96 & 87 & 0.63 & 3 & 2 & 0.91 & 0.47 & 0.25 & 0.36 \\
\hline VLG2-E-1 & 96 & 92 & 0.57 & 7 & 4 & 0.96 & 0.55 & 0.54 & 0.46 \\
\hline VLG2-R-1 & 96 & 94 & 0.22 & 27 & 10 & 0.98 & 0.84 & 0.84 & 0.82 \\
\hline
\end{tabular}


Supplemental Table 3. Continued.

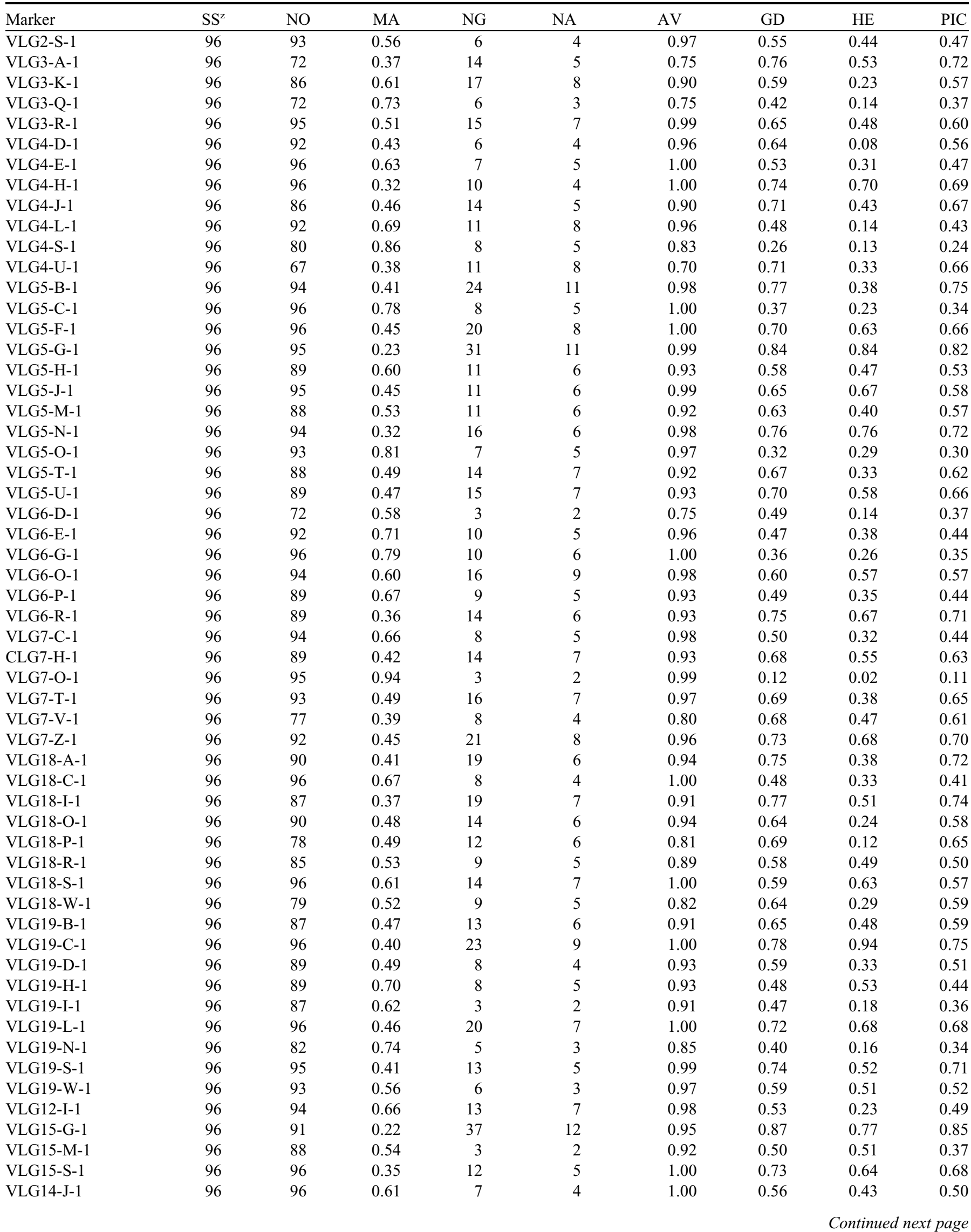


Supplemental Table 3. Continued.

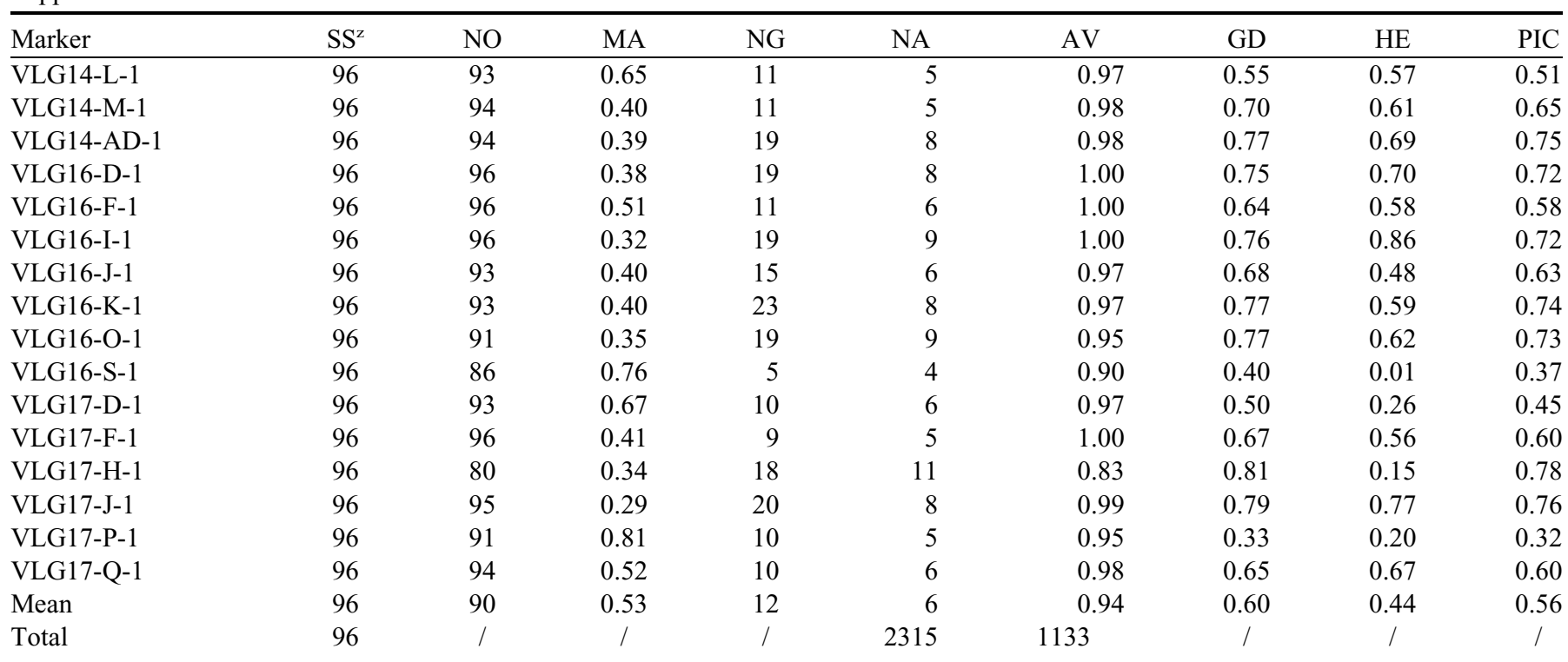

${ }^{\mathrm{z}} \mathrm{SS}=$ sample size; $\mathrm{NO}=$ number of observer alleles; $\mathrm{MA}=$ major allele frequency; $\mathrm{NG}=$ number of genotypes; AV = availability; GD = gene diversity; $\mathrm{HE}=$ heterozygosity; PIC = polymorphism information content. 